\title{
Cerâmicas da Tradição Borda Incisa/Barrancóide na Amazônia Central ${ }^{*}$
}

\author{
Helena Pinto Lima** \\ Eduardo Góes Neves***
}

\begin{abstract}
LIMA, H.P.; NEVES, E.G. Cerâmicas da Tradição Borda Incisa/Barrancóide na Amazônia Central. R. Museu Arq. Etn., São Paulo, n. 21, p. 205-230, 2011.
\end{abstract}

Resumo: A sequência crono-estilística ligada à variabilidade cerâmica na Amazônia central tem sido foco de debates há tempos. Algumas hipóteses clássicas sobre a ocupação humana na área são agora reavaliadas através de uma ampla gama de dados empíricos aliada a um novo corpus teórico-analítico. Este artigo apresenta parte dos resultados das análises cerâmicas levadas a cabo por uma pesquisa de doutorado no âmbito do Projeto Amazônia Central (MAEUSP). Os dados aqui apresentados apontam maneiras de se reacessar o uso de conceitos caros à arqueologia brasileira, como as fases e tradições, sob uma perspectiva diferenciada. Na área de confluência dos rios Negro e Solimões, tais conceitos permitiram a construção de uma cronologia de ocupação baseada no entendimento das relações existentes entre as fases Açutuba, Manacapuru e Paredão, relacionadas à Tradição Borda Incisa/Barrancóide da Amazônia.

Palavras-chave: Arqueologia amazônica - Cerâmicas arqueológicas Cronologia - Amazônia Central.

\section{Introdução}

arqueologia amazônica sempre despertou o fascínio de viajantes e estudiosos, principalmente pela natureza de seus vestígios. A diversidade paisagística, somada à quanti-

$\left.{ }^{*}\right)$ Este artigo apresenta parte dos resultados da tese de doutoramento defendida pela primeira autora no Museu de Arqueologia e Etnologia da Universidade de São Paulo (MAEUSP). O estudo foi financiado pela Fundação de Amparo à Pesquisa do Estado de São Paulo (FAPESP).

(*) Programa de Pós-Graduação em Antropologia Social/ Museu Amazônico - Universidade Federal do Amazonas (UFAM).<lenalima@hotmail.com>

${ }^{(* * *)}$ Museu de Arqueologia e Etnologia da Universidade de São Paulo (MAE-USP).<edgneves@usp.br> dade, acuidade tecnológica e o elevado apreço estético das cerâmicas que ali se encontram conferem a esta região um caráter único no contexto arqueológico brasileiro. Tais características levaram pesquisadores a suscitarem as mais diversas hipóteses sobre a ocupação da Amazônia, por vezes encarada como chave para o entendimento do povoamento do continente sul-americano (Brochado 1989; Lathrap 1970a).

Seguindo uma tendência geral da arqueologia brasileira recente, os trabalhos realizados nas décadas de 1950 a 1970 na região amazônica têm sido revistos com base em novos olhares disciplinares. Assim sendo, na Amazônia central - foco do presente artigo - a cronologia local e regional de ocupação pré-colonial tem sido paulatinamente reavaliada, principalmente 
através de pesquisas desenvolvidas no âmbito do Projeto Amazônia Central (PAC) que é vinculado ao Museu de Arqueologia e Etnologia da Universidade de São Paulo (MAE-USP). Este projeto vem atuando nos municípios de Manaus e Iranduba, estado do Amazonas, desde 1995. Durante este período, foi identificada mais de uma centena de sítios arqueológicos, sendo que parte deles já foi sistematicamente pesquisada através de trabalhos de mapeamento, delimitação, escavação e análises (Neves 2000, 2003, 2008; Neves et al. 2007).

Os objetivos gerais do projeto são o estabelecimento de tamanho e forma dos assentamentos, a reconstrução da densidade e duração das ocupações e o refinamento da cronologia da área de confluência dos rios Negro e Solimões (Fig. 1), visando testar e rever algumas das principais hipóteses de ocupação da Amazônia (Meggers 1971, 1990; Meggers; Evans 1957, 1961, 1983; Lathrap 1970a, 1970b; Brochado 1989). Dentre iniciações científicas, mestrados e doutorados, o PAC tem contribuído para reavaliar antigas questões propostas, testando diferentes modelos propostos a partir de novos dados e correntes interpretativas.

Este artigo se dedica a apresentar especificamente os resultados de análises cerâmicas desenvolvidas no âmbito de uma tese de doutoramento ligada ao PAC (Lima 2008). Embora o presente artigo se dedique apenas às questões que aludem à cerâmica, a referida pesquisa abordou diversos outros pontos, congregando diferentes análises para que os resultados aqui apresentados pudessem dar conta de estabelecer uma cronologia de ocupação sólida para a região em estudo. Este artigo, portanto, pretende debruçar-se especificamente sobre as sequências arqueológicas locais, focada nos materiais da tradição cerâmica denominada Borda Incisa (Meggers; Evans 1961, 1983; Hilbert 1968; Lima 2008) ou Barrancóide (Gomes 2002; Lathrap 1970a, 1970b; Lima 2008), para possibilitar discussões sobre uma territorialidade mais ampla desta tradição tecnológica.

Na Amazônia central, foi o arqueólogo alemão Peter Hilbert o responsável pela identificação e caracterização do registro arqueológico ali encontrado (1968). Através do estabelecimento de sequências seriadas, nas quais se observavam mudanças graduais na cerâmica, observou-se que a crono-estratigrafia seria caracterizada por rupturas entre os conjuntos cerâmicos. Estes conjuntos estariam associados a uma sequência cronológica de acordo com aquela previamente proposta através dos horizontes (posteriormente chamados de tradições), de Meggers e Evans (1961).

Dentro dos conjuntos identificados por Hilbert (1968), as fases Manacapuru e Paredão forneceram seis datações radiocarbônicas que, em conjunto com suas características decorativas, as situaram na tradição Borda Incisa, o segundo horizonte estilístico definido por Meggers e Evans, datado entre 100 e 800 d.C. (idem). Estes dados eram inéditos à época, uma vez que materiais associados a essa tradição eram conhecidos apenas no Orinoco e baixo Amazonas. Hilbert associou à tradição Borda Incisa o aparecimento das primeiras urnas para enterramento secundário, e os primeiros assadores de mandioca (1968: 273).

Nas expectativas do modelo de D. Lathrap (1970a, 1970b), haveria uma indicação de continuidade entre os conjuntos locais, no âmbito da Amazônia central. Assim, segundo o autor, a tradição Borda Incisa seria, na verdade, uma representação da série Barrancóide encontrada na Venezuela e Caribe, que teria se desenvolvido inicialmente na Amazônia central e, mais tarde, migrado para o norte da América do Sul (Lathrap 1970a: 130-132). Para ele, estava claro que as cerâmicas da fase Manacapuru seriam um correlato material dos povos falantes de línguas do tronco Arawak, que teriam partido da Amazônia central (seu locus de origem) e colonizado, em diferentes levas migratórias, a Bacia do Orinoco e o Caribe. Junto com a tecnologia cerâmica, classificada por Lathrap como Barrancóide e não Borda Incisa, esses povos teriam levado a esta porção setentrional do continente outros elementos, tais como as técnicas agrícolas do cultivo de mandioca e a própria língua.

Borda Incisa ou Barrancóide, as características distintivas destas cerâmicas seriam bordas largas, com o topo achatado, produzidas a partir de um aumento da espessura do centro do vaso, resultando em uma silhueta seccional triangular. A superfície destas bordas seria geralmente 
decorada com incisões. Há, em alguns casos, pintura ou engobo vermelho decorando o interior ou o exterior de alguns vasos. Além das fases definidas por Hilbert, a tradição Borda Incisa englobaria outras fases cerâmicas nas bacias do Amazonas e Orinoco, na Venezuela.

$\mathrm{Na}$ Amazônia central, essa tradição seria representada pelas fases Manacapuru e Paredão. A primeira, caracterizada por grande variabilidade formal, mas sempre com as bordas expandidas características à tradição. $\mathrm{O}$ vasilhame é temperado com o cauixi, uma esponja de água doce comumente encontrada em rios de águas pretas. A decoração, um tanto rebuscada, consistiria essencialmente na modelagem de figuras abstratas, zoomorfas e antropomorfas, em incisões de todos os tipos e também no engobo. Já a fase Paredão teria uma variabilidade formal pequena, principalmente quando comparada com outras fases cerâmicas da Amazônia. As formas mais comuns seriam os vasos com alça (fruteiras), cuias, grandes urnas funerárias e panelas sem decoração. A decoração, mais rara, era feita através de pintura vermelha com motivos geométricos em espiral e em gregas, e apêndices antropomorfos (sempre aplicados nas urnas). $\mathrm{O}$ tempero mais utilizado seria também o cauixí.

Em pesquisa recentemente desenvolvida no âmbito PAC, a cronologia inicial proposta para a região por Hilbert (1968) foi reavaliada. Seu refinamento se deu através de uma série de datações radiocarbônicas, que indicou uma grande lacuna temporal entre dois contextos anteriormente considerados como pertencentes à fase Manacapuru. Além disso, os dados contextuais, cronológicos e de variabilidade cerâmica examinados levaram a uma divisão da fase Manacapuru em duas fases cerâmicas distintas, denominadas Açutuba e Manacapuru (Lima et al. 2006).

Desta forma, pretendemos neste artigo oferecer um quadro descritivo detalhado sobre as cerâmicas encontradas na Amazônia central relacionadas à tradição Borda Incisa ou Barrancóide. Mais do que discutir nomenclaturas e significados, a intenção aqui é reunir os dados relativos a essas cerâmicas, fornecendo subsídios sólidos para discussões mais abrangentes sobre a história de ocupação da área de confluência dos rios Negro e Solimões e da Amazônia como um todo.

\section{A escolha dos sítios arqueológicos e a metodologia de análise}

Os sítios arqueológicos abordados no presente estudo situam-se na área de confluência dos rios Negro e Solimões, área piloto do Projeto Amazônia Central (Fig. 1). Esta região, além de ser chave para a compreensão de uma série de questões sobre a ocupação humana na Amazônia como um todo, representa também um verdadeiro mosaico paisagístico da diversidade encontrada nesta Hiléia. Desta forma, os sítios selecionados encontram-se distribuídos de maneira a oferecer um parâmetro de tal heterogeneidade, tanto regional, como crono-estratigráfico:

1) distribuição regional - os sítios arqueológicos estudados representam uma boa amostra regional, abrangendo tanto as margens dos rios Negro e Solimões, como a área de interflúvio (Fig. 1). Desta forma, objetivou-se detectar os padrões de variabilidade em sítios pertencentes a diferentes nichos geográficos, dando luz às interpretações sobre seus usos e funções. Além disso, a partir do trabalho em tais sítios, pôde-se ter uma idéia da variabilidade regional da Tradição Borda Incisa dentro de uma ampla área da Amazônia.

2) crono-estratigráfico - os sítios arqueológicos apresentam níveis de ocupação supostamente relacionados às fases Açutuba, Manacapuru e Paredão na Amazônia central (Tabela 1). Foram abordados contextos uni e multicomponenciais, associados ou não com as Terras Pretas. Esses diferentes contextos permitiram o estabelecimento de comparações intra-sítio e regionais. Vale lembrar que as associações dos contextos estudados às fases cerâmicas não são dadas a priori: elas são hipotéticas. O objetivo da pesquisa foi justamente melhor defini-las e relacioná-las dentro dos diferentes contextos estratigráficos e espaciais. 


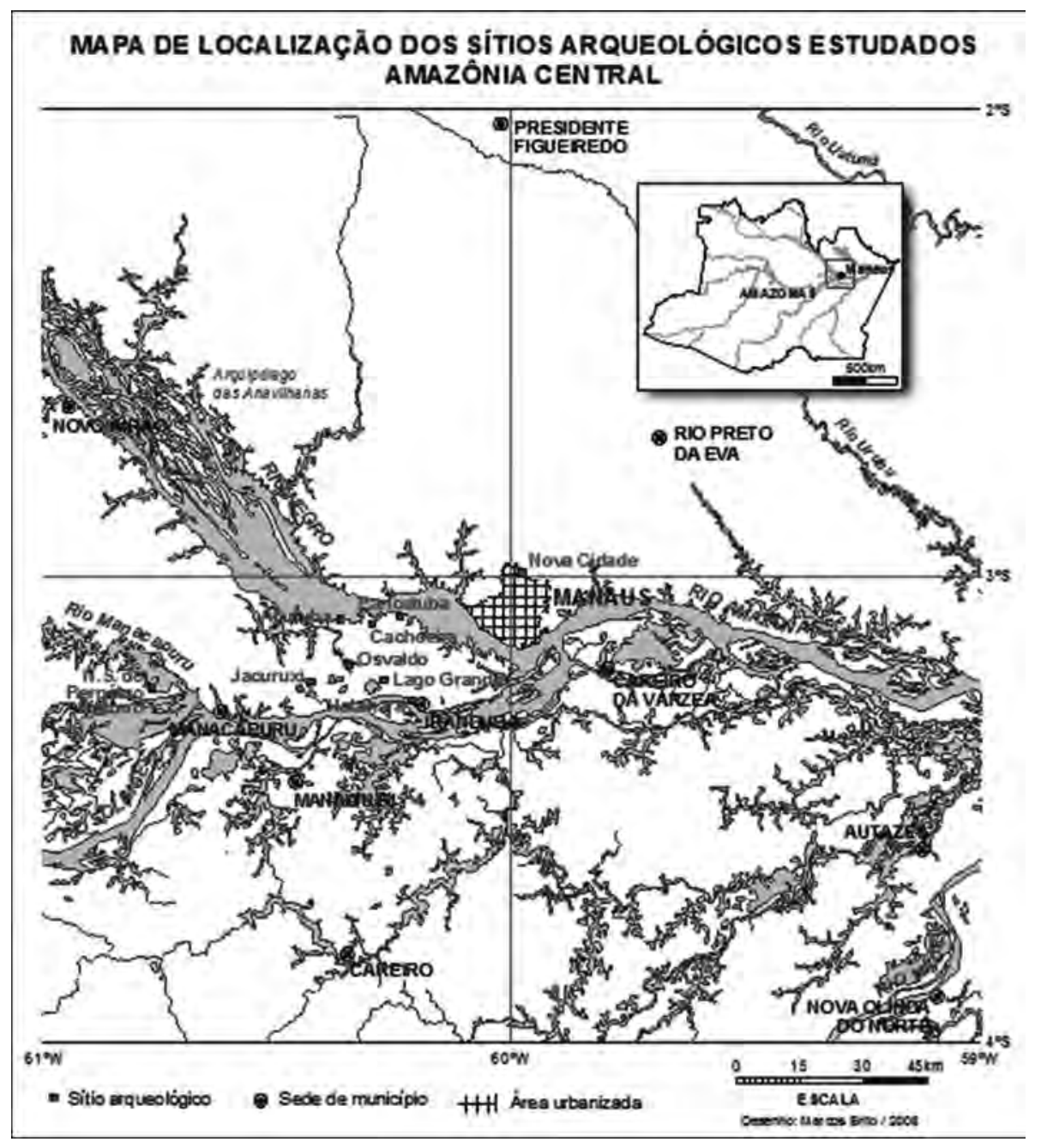

Fig. 1. Sítios arqueológicos estudados, situados na área de confluência dos rios Negro e Solimões, municípios de Manaus, Iranduba e Manacapuru/AM.

Sítios arqueológicos / Ocupações hipotéticas

Fase Açutuba Fase Manacapuru

Fase Paredão

\begin{tabular}{l|l|l}
\hline \hline Açutuba & & \\
Cachoeira & & \\
Paricatuba & & \\
NSP Socorro & & \\
Hatahara & & \\
Jacuruxi & & \\
Lago Grande & & \\
Osvaldo & & \\
Nova Cidade & \\
\hline
\end{tabular}

Tabela 1. Sítios cerâmicos estudados e as fases a eles correlacionadas, da Tradição Borda Incisa. 
Os sítios pesquisados resultam de levantamentos realizados no âmbito do Projeto Amazônia Central, bem como de outros projetos de resgate arqueológico. ${ }^{1}$ Cada sítio arqueológico sofreu uma quantidade diferenciada de intervenções. Foram abordados tanto os materiais provenientes de sítios que vêm sendo sistematicamente escavados há mais de dez anos, como é o caso de Açutuba e Hatahara; como também sítios que passaram apenas por delimitações preliminares e tímidas escavações.

Os trabalhos de campo desenvolvidos nos sítios arqueológicos pesquisados tiveram diferentes níveis de abordagem, variando de acordo com os problemas e perguntas, gerais ou pontuais, colocadas frente ao registro, mas seguiram, sempre, a mesma orientação metodológica empregada na área do PAC. Trata-se de uma metodologia adequada tanto a sítios com grandes dimensões quanto a sítios em áreas de floresta, típicos da Amazônia. Através dos trabalhos de campo, objetivou-se estabelecer o tamanho, densidade e duração de ocupação dos sítios arqueológicos na região. As intervenções foram orientadas a partir de algumas etapas básicas: 1) estabelecimento do grid; 2) topografia; 3) verificação de vestígios em superfície; 4) delimitação do sítio através de linhas de tradagens e 5) escavações.

Dessas atividades resultaram muitas toneladas de vestígios arqueológicos, dos quais um total de um total de 7.789 fragmentos cerâmicos ou vasos inteiros foi analisado. Lembrando que estes encontram-se distribuídos de maneira não uniforme em nove sítios arqueológicos da área de pesquisa do PAC (Tabela 2).

Se classificações, em última instância, são não mais do que ferramentas usadas para se atingir certos objetivos, (neste caso, históricos), torna-se mister que os métodos analíticos empregados sejam flexíveis a ponto de variar de acordo com os problemas de pesquisa que se colocam frente ao universo que se pretende acessar.

(1) Os resgates cujos sítios arqueológicos foram diretamente incorporados à pesquisa foram o Gasoduto Coari-Manaus e o "Resgate emergencial do sítio Nova Cidade" (Neves e Costa 2001; Neves et al. 2004).

\begin{tabular}{lc}
\hline $\begin{array}{c}\text { Sítios } \\
\text { arqueológicos }\end{array}$ & $\begin{array}{c}\text { Qtd. de fragmentos } \\
\text { analisados }\end{array}$ \\
\hline \hline Açutuba & 2622 \\
Cachoeira & 55 \\
Paricatuba & $1^{*}$ \\
NSP Socorro & $232+1^{*}$ \\
Hatahara & 659 \\
Jacuruxi & 3139 \\
Osvaldo & 363 \\
Lago Grande & 951 \\
Nova Cidade & $21 *$ \\
\hline * vasos inteiros &
\end{tabular}

Tabela 2. Quantidade de fragmentos ou vasos inteiros analisados em cada coleção arqueológica.

O caso amazônico aqui tratado apresenta uma particularidade, pois, em decorrência de diversos fatores, tanto de ordem físico-ambientais, quanto históricos, as análises de cultura material foram sempre voltadas ao estudo privilegiado de uma categoria de objetos apenas, as cerâmicas.

Esta pesquisa também viu nas cerâmicas uma fonte privilegiada de informações culturais e históricas. O tamanho dos depósitos, a profusão de sítios e sua variabilidade (tanto formal quanto tecnológica e decorativa) foram fatores que nos levaram a olhar a cerâmica também de modo preferencial, mas através de um ângulo peculiar, relacional. Seu potencial informativo, tanto maior quando contrastado com outras linhas de evidência (Schaan 2007: 87), faz com que as análises cerâmicas tenham um papel importante na construção do conhecimento acerca de um passado cultural. Desde, é claro, que elas não sejam vistas como fonte única de informações, tampouco que o estabelecimento de tipologias se torne um fim em si próprio. Ao contrário, é essencial que estas análises sejam "desengessadas" e conjugadas a outras fontes de dados. Isso é uma tendência em atuais pesquisas arqueológicas no Brasil (Almeida 2008; Bandeira 2008; Schaan 2004; Dias 2003; Machado 2005; Moraes 2007; Silva 2000). 
Assim sendo, as primeiras etapas do processo analítico, referentes à caracterização do sistema tecnológico tratado, foram voltadas à definição da cadeia operatória, com vistas à identificação das escolhas tecnológicas a ela vinculadas. Para tanto, foi desenvolvida uma metodologia na qual as diferentes etapas do processo de produção cerâmica eram agregadas em categorias de atributos, sem quaisquer relações de hierarquização entre elas, registrados em uma ficha de análise, posteriormente tratadas estatisticamente. As análises estatísticas foram realizadas pelo Instituto de Pesquisas Energéticas e Nucleares (IPEN) e pelo Centro de Estatística Aplicada (IME-USP) (Borges; Coelho 2003; Peixoto; Okura 2003).

Para que os agrupamentos fossem viáveis, tanto fragmentos quanto vasos inteiros ou parcialmente remontados foram tratados segundo os mesmos parâmetros classificatórios, e foram agrupados em tipos a partir de suas semelhanças. Os critérios utilizados para definição dos tipos foram amplamente discutidos ao longo da pesquisa (Lima 2008:150-189): trata-se fundamentalmente de uma classificação qualitativa segundo modos de forma, pasta e decoração; da contraposição desta aos dados quantitativos dos atributos observados em cada fragmento ou vaso, ajustados através de uma estatística descritiva; e de uma posterior análise estilística estrutural. A combinação dos resultados dessas três etapas gerou os agrupamentos (tipos). Variações consistentes dentro de cada tipo foram reagrupadas em subtipos. As variações que geraram subtipos são de natureza tanto morfológica quanto tecnológica ou decorativa.

Foram sugeridas tipologias independentes para cada sítio arqueológico analisado (Lima 2008: 405-514). Dado que se trata de um mesmo universo material - Borda Incisa -, há fortes semelhanças entre os conjuntos de diferentes sítios, que foram posteriormente re-agrupados de modo a compor a cronologia cerâmica da região decomposta nas fases arqueológicas. Desta forma, as tipologias das coleções foram ordenadas cronologicamente, com início nos conjuntos mais antigos com materiais associados à fase Açutuba, e seguindo para os contextos mais recentes, com cerâmicas das fases Manacapuru e Paredão, respectivamente (Fig. 2).
Vale lembrar que a amostragem analisada sempre será pouco representativa frente ao universo que se pretende interpretar, a tipologia aqui proposta é flexível, podendo ser alterada na medida em que novos materiais forem analisados. Também, nem todas as coleções analisadas resultaram em tipologias, pois para o estabelecimento dos tipos é necessário que os fragmentos apresentem um grau mínimo de preservação, nem sempre visto nos sítios estudados. Ao final, ficaram estabelecidos vinte tipos cerâmicos para a Tradição Borda Incisa, sendo dezesseis vinculados à fase Açutuba, treze à fase Manacapuru e dez à Paredão (Tabela 3).

\begin{tabular}{ccc}
\hline Sítios & $\begin{array}{c}\text { No de } \\
\text { tipos }\end{array}$ & Fases relacionadas \\
\hline Açutuba & 24 & Açutuba Manacapuru \\
Hatahara & 12 & Açutuba Manacapuru \\
NSP Socorro & 1 & Manacapuru \\
Jacuruxi & 14 & Açutuba Manacapuru \\
Cachoeira & 2 & Manacapuru \\
Paricatuba & 1 & Manacapuru \\
Osvaldo & 9 & Manacapuru \\
Lago Grande & 8 & Paredão \\
Nova Cidade & 6 & Paredão \\
\hline
\end{tabular}

Tabela 3. Os sítios analisados de acordo com os tipos cerâmicos identificados e as fases relacionadas.

\section{As fases cerâmicas}

Os primeiros esforços em qualificar e criar tipologias para as fases cerâmicas encontradas na Amazônia central foram empreendidos, na década de 60, pelo arqueólogo alemão Peter Hilbert (1968), que foi, junto com Mário Simões, um dos principais expoentes dos pressupostos teórico-interpretativos dos trabalhos de Betty Meggers e Clifford Evans na região Amazônica. Nestes trabalhos, Hilbert encontrou nesta área materiais qualificados em três fases cerâmicas distintas: Manacapuru, Paredão - ligadas à tradição Borda Incisa - e Guarita, mais recente 


\begin{tabular}{|c|c|c|c|}
\hline \multirow[b]{2}{*}{ Tipos cerâmicos } & \multicolumn{3}{|c|}{ Fases } \\
\hline & Açu tu ba & Manacapuru & Paredão \\
\hline tampas ou ban quet & $\begin{array}{l}\text { reconstituiçāa năo } \\
\text { possivel }\end{array}$ & & \\
\hline vasilhas com flange & $\rightleftarrows$ & & \\
\hline vasos com colo & $\longleftrightarrow$ & & \\
\hline gamelas poligonais & $\begin{array}{l}\text { reconstituição não } \\
\text { possivel }\end{array}$ & & \\
\hline cuias com borda int & & & \\
\hline estatuetas & $\begin{array}{l}\text { reconstituiçâa não } \\
\text { possivel }\end{array}$ & $\begin{array}{l}\text { reconstituiçăo nâo } \\
\text { possivel }\end{array}$ & \\
\hline vasilhas com flange & & & \\
\hline vasos globulares co & & & \\
\hline vasilhas de contorn & & & \\
\hline vasos com contorno & & & \\
\hline vasos globulares (c & & & \\
\hline cuias & 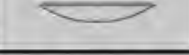 & & \\
\hline assad ores & & & \\
\hline alguidares & & & \\
\hline pratos & & & \\
\hline tigelas & & & \\
\hline vasilhas com boca $i$ & & & \\
\hline cuia com pedestal & & $\begin{array}{l}\text { reconstituiçăo nâo } \\
\text { possivel }\end{array}$ & \\
\hline cesta com alça & & & \\
\hline potes com gargalo & & & \\
\hline
\end{tabular}

Formas identificada na tipologia Paredão de Moraes (2006) para cerâmicas de sítios arqueológicos do Lago do Limão, mas nâo encontradas nos materiais analisados.

Fig. 2. Tipos cerâmicos identificados, formas identificadas e relações cronológicas entre eles, de acordo com as fases propostas. 
e vinculada à tradição Polícroma da Amazônia. Utilizando-se do método da seriação cerâmica, Hilbert definiu seis tipos para a indústria Manacapuru e também seis para as cerâmicas Paredão. Posteriormente, esta cronologia cerâmica foi refinada com os trabalhos desenvolvidos pelo PAC na região. Como já mencionado, recentemente, foi proposta uma nova fase também ligada à Tradição Borda Incisa / Barrancóide, a fase Açutuba (Lima et al. 2006).

Com base nas descrições detalhadas de cada sítio arqueológico, de cada coleção tratada e das tipologias resultantes, procedeu-se à caracterização das fases cerâmicas, cujos componentes artefatuais são apresentados a seguir.

\section{Cerâmicas da fase Açutuba}

Materiais relacionados a esta fase aparecem em quantidade considerável, o que poderia remeter a uma ocupação mais intensa, apenas em dois sítios: Hatahara e Açutuba. Apesar disso, se percebe que ela se encontra espalhada por vários locais da Amazônia central, em torno de dois mil anos atrás, em pequenas concentrações de material, sempre em substratos profundos e em matrizes de solo não antrópicas. Esses materiais também foram encontrados em alguns dos sítios trabalhados por esta pesquisa, como Osvaldo e Lago Grande. Em relação aos locais em que o material aparece em profusão, tais concentrações, apesar de não serem tão bem compreendidas, podem ter uma sequência cronológica bastante longa e, quiçá, contínua. Apesar de serem assentamentos sedentários, seu tamanho é reduzido. Embora haja uma grande quantidade de cerâmica com funções domésticas e utilitárias, impressiona o número de fragmentos decorados em relação ao total, o que pode ter implicações interessantes para a compreensão de tal variabilidade.

Vinculada a essa fase cerâmica, nos sítios que indicam uma ocupação mais intensa, encontra-se uma série de estruturas associadas a esses materiais. Ainda que não tenhamos entendido perfeitamente suas funções, elas aparentam ser de dois tipos. Um deles foi interpretado como uma espécie de "midden" (lixeira), um acúmulo intencional de refugos de uso cotidiano, que tem como diferencial a grande quantidade de fragmentos decorados em sua composição, da mesma forma que em todo o piso de ocupação encontrado em ambos os sítios. O outro tipo, comumente percebido como feições de solo produzidas em diferentes eventos deposicionais, conta com uma altíssima quantidade de material cerâmico decorado, em número bastante superior ao encontrado no piso de ocupação. Tais feições não puderam ter sua finalidade inferida, mas certamente elas se inserem em um contexto de transformação da paisagem vigente. A dificuldade de acesso, principalmente por ocupar camadas estratigráficas profundas, se coloca como um fator de impedimento para que se encontrem outros sítios que apresentem um maior adensamento de materiais, e que possibilitem inferências mais precisas acerca destas estruturas.

Além de serem apenas dois os sítios encontrados que forneceram cerâmicas em grande quantidade, nem sempre os materiais estão bem preservados. Ao contrário do que acontece no sítio Açutuba, as condições do sítio Hatahara propiciaram ao contexto um melhor estado de preservação, permitindo que fossem identificados vestígios faunísticos (principalmente de quelônios) em meio ao piso de ocupação. Entretanto, não foram encontrados resquícios ósseos humanos, em nenhuma circunstância. Aliado a isso, é importante salientar a ausência de aparatos funerários em meio à indústria cerâmica, ao menos dentre as funções que puderam ser inferidas.

As cerâmicas que compõem a fase Açutuba apresentam pastas com características variadas, mas quase sempre são leves e porosas. Alguns tipos de pasta se destacam. Uma primeira, de cor branca, aparece sempre associada a uma categoria de vasilhas, com formas de contorno complexo e com pintura policrômica. A segunda, também bastante característica dessa fase, tem um forte tom alaranjado e sua leveza e porosidade se destacam entre as demais. Esta pasta apresenta uma grande abundância de cauixi como tempero, apesar de este estar presente na maior parte dos fragmentos. Outro traço marcante desta pasta é a sua associação com a pintura e com alguns tipos cerâmicos bem caracte- 
rísticos desta fase, como as estatuetas modeladas e as formas poligonais. As demais pastas, que ordinariamente aparecem distribuídas por todas as categorias, variam em tonalidades de bege-alaranjado, laranja-amarronzado e cinza. Além do cauixi, apresentam em menor proporção outros anti-plásticos misturados, como grãos de quartzo e hematita, componentes das próprias argilas. Outros aditivos também são utilizados, podendo aparecer em menor proporção junto ao cauixi ou podem, em casos mais raros, ser o componente principal do tempero. São eles, em ordem de frequência, o cariapé, o caco moído e nódulos de argila.

Também as queimas apresentam certa variação no tocante às formas e, principalmente, tipos de pastas. No entanto, observa-se uma maior frequência de queimas em ambientes oxidantes. Como exemplo, as pastas anteriormente citadas, nas cores branca e laranja-forte, são sempre oxidadas, enquanto as demais variedades de pasta apresentam uma grande variabilidade. Devido às condições gerais de preservação, que variam entre os sítios e, talvez, à sua antiguidade, as características de sua superfície nem sempre puderam ser observadas. Dessa forma, o tratamento de superfície mais detectado foi o alisamento seguido pelo escovado, em detrimento de outras técnicas mais elaboradas, como a aplicação de resinas ou o polimento.

Essas cerâmicas são caracterizadas por uma variação formal extremamente ampla, com certa tendência para as formas irrestritivas. Ao rebuscamento da decoração, soma-se uma grande complexidade dos contornos dos vasos. A região próxima da borda (pescoço ou flange) é sempre mais espessa do que o corpo da vasilha, de maneira geral, sendo uma região preferencial para a aplicação da decoração. Esta, quando ocorre no bojo dos vasos, é uma extensão dos motivos das bordas, relacionada à composição da decoração total da vasilha. Neste mesmo sentido, os flanges labiais, que ocorrem com bastante frequência, são locais onde a decoração também é recorrente: todos apresentaram algum tipo de tratamento decorativo.

Os flanges labiais, assim como os lábios expandidos, consistem numa acentuada expansão externa da borda, a partir de um ponto de inflexão que geralmente dista entre 2 e $5 \mathrm{~cm}$ do lábio. São fabricados em separado, obtidos pela união de dois ou mais roletes, que são posteriormente afixados no corpo do vaso, já no estágio de secagem. A união entre o rolete do corpo e o rolete do flange é feita através de um encaixe: fissuras em sentido oposto ao do rolete, obtidas por um instrumento pontiagudo ou pela própria unha, são feitas sobre as extremidades a serem unidas, criando um encaixe. Uma vez afixado o flange, o ponto de união é recoberto por uma camada de argila em estado bastante plástico, e posta para secar. Flanges labiais são muito frequentes entre os materiais da fase Açutuba, podendo ser considerados como um traço diagnóstico desta fase cerâmica. Uma variada gama de técnicas e motivos decorativos são aplicados em sua face superior, a mais visível. Entre as técnicas utilizadas, excisões, incisões e modelagens muitas vezes se associam a apêndices zoomórficos. Os lábios são sempre planos e cortados.

Além dos flanges labiais, outros elementos morfológicos e estruturais característicos são flanges mesiais, apliques, apêndices modelados e estatuetas. Estes últimos, em geral com fins decorativos, são produzidos através de modelagem. Com exceção deles, a técnica de produção dos vasos é sempre a de sobreposição de roletes.

Os flanges mesiais são formados pela adição de um ou mais roletes a meia altura da parede externa dos vasos, dando-lhes uma forma bastante singular. Embora sejam um elemento típico da fase Guarita da Tradição Policroma da Amazônia, os flanges mesiais ocorrem também entre os materiais da fase Açutuba, em pequena quantidade. É interessante notar que um elemento definidor da fase Guarita ocorre também na fase Açutuba, mas não nas fases Manacapuru e Paredão, intermediárias a elas.

Esta indústria se utiliza largamente da modelagem como recurso decorativo. Trata-se, em geral, de apêndices aplicados na borda ou no lábio dos vasos, representando figuras antropomorfas, zoomórficas (especialmente répteis e aves), e abstratas. Estão sempre associados a outras técnicas decorativas, como incisões de todos os tipos e pintura. Em pratos ou vasilhas muito abertas os apêndices são uma extensão 
modelada de flanges labiais. Ocorrem também em grandes tigelas, provavelmente adquirindo função utilitária, como alça.

Traço diagnóstico das cerâmicas Açutuba é o rebuscamento das decorações plásticas. As incisões, finas ou largas e, na maioria das vezes, em linhas simples, são o componente decorativo mais recorrente nestas cerâmicas. Estão presentes na quase totalidade dos fragmentos decorados, associadas com frequência a outras técnicas decorativas como a modelagem e a pintura. Um tipo característico de incisão que aparece quase sempre nestes materiais é aquele executado sobre a superfície da cerâmica já seca e queimada, e com engobo vermelho. É uma prática realizada com uso de instrumento pontiagudo, dando um efeito bem diverso daquela feita antes da queima. Esta técnica é comumente encontrada com excisões, nos materiais da fase Marajoara (tradição Policroma).

Aparecem também excisões e acanalados, sendo estes últimos geralmente aplicados na face externa dos vasos, na região logo abaixo do flange labial ou do pescoço. Podem ser recobertos por engobo vermelho ou por pintura em cores. A quantidade de fragmentos pintados é proporcionalmente inferior àqueles que recebem decoração plástica, mas a presença desta técnica em materiais tão antigos na Amazônia central chama atenção por diversos fatores, alguns deles já mencionados. Suas características técnicas são a aplicação de uma prévia camada de engobo branco sobre a superfície do pote, e posterior pintura em linhas finas, faixas grossas ou em áreas, em diferentes tonalidades de alaranjado, vermelho, marrom e vinho. São muito semelhantes, em diversos aspectos, às cerâmicas Pocó, do baixo Amazonas. A estes conjuntos foi atribuída uma influência Saladóide, como se verá adiante. Cabe salientar que, a esta pintura, quando encontrada em contextos profundos, pode ser atribuído um caráter diagnóstico desta fase cerâmica (Figs. 3 e 4).

\section{Cerâmicas da fase Manacapuru}

Os sítios em que se encontram materiais relacionados à fase Manacapuru são bem mais numerosos do que os sítios com materiais Açu- tuba. Possuem geralmente depósitos mais extensos e, via de regra, estão sobre solos antrópicos, as terras pretas de índio. É interessante também que esta associação entre materiais da fase Manacapuru, o tamanho dos sítios e a presença de terra preta já havia sido feita por Hilbert (1968) e confirmada pelos trabalhos realizados pelo Projeto Amazônia Central, ao encontrar sítios com estas mesmas características, como os sítios Osvaldo, Açutuba e Hatahara, sem mencionar muitos outros que não constam neste artigo.

Mais interessante ainda é notar que também foram encontrados sítios contendo materiais associados à fase Manacapuru com datações antigas, em matrizes de solo modificadas antropicamente, com depósitos rasos e que ainda não possuem as tonalidades peculiares às terras pretas, sendo mais claras e com menor densidade de material orgânico, o que indicaria um caminho intermediário no processo de constituição desses solos. Conforme estabelecido pelos parâmetros de Hilbert, e seguido pelo PAC durante certo tempo, esta fase cerâmica era pensada dentro de uma sequência cronológica que ia do séc. VI ao IX, de acordo com os estudos dos sítios até então realizados. No entanto, evidências de materiais mais antigos desta fase, advindos de sítios identificados a partir da intensificação dos trabalhos, como o Jacuruxi e Nossa Senhora do Perpétuo Socorro, acabaram por fornecer datas recuadas, este último entre os séculos I e III. Dentro de uma perspectiva normativista seria compatível com a ocupação Açutuba, mas foi justamente o contexto observado em sua totalidade que nos permitiu inferir sua filiação a uma e não à outra fase: tamanho do sítio, presença de terras pretas em processo de formação, ausência de características diagnósticas no material cerâmico (como a policromia, por exemplo), entre outros. Este sítio é uma peça-chave para entender a relação que há entre estas duas fases.

Estudos realizados no âmbito do PAC também têm caracterizado formas de assentamento circulares relacionadas à fase Manacapuru, como é o caso do sítio Osvaldo (Abreu 2000; Portocarrero 2007).

Quando se pensa na caracterização das cerâmicas deste conjunto, há uma questão 

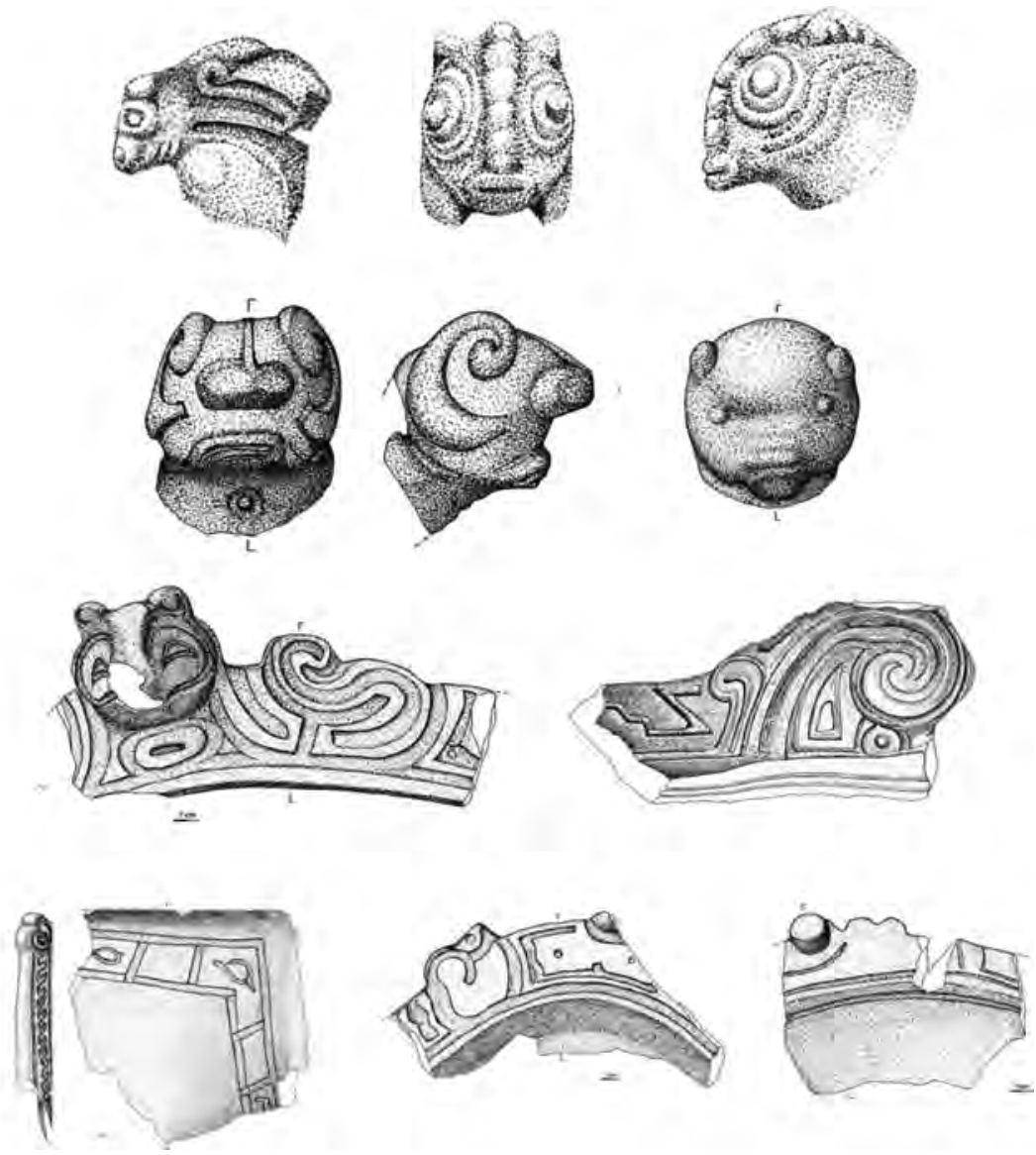

Fig. 3. Apliques modelados e fragmentos decorados associados à fase Açutuba, presentes nos sítios Açutuba e Hatahara (desenhos: Val Moraes e Marcos Brito).
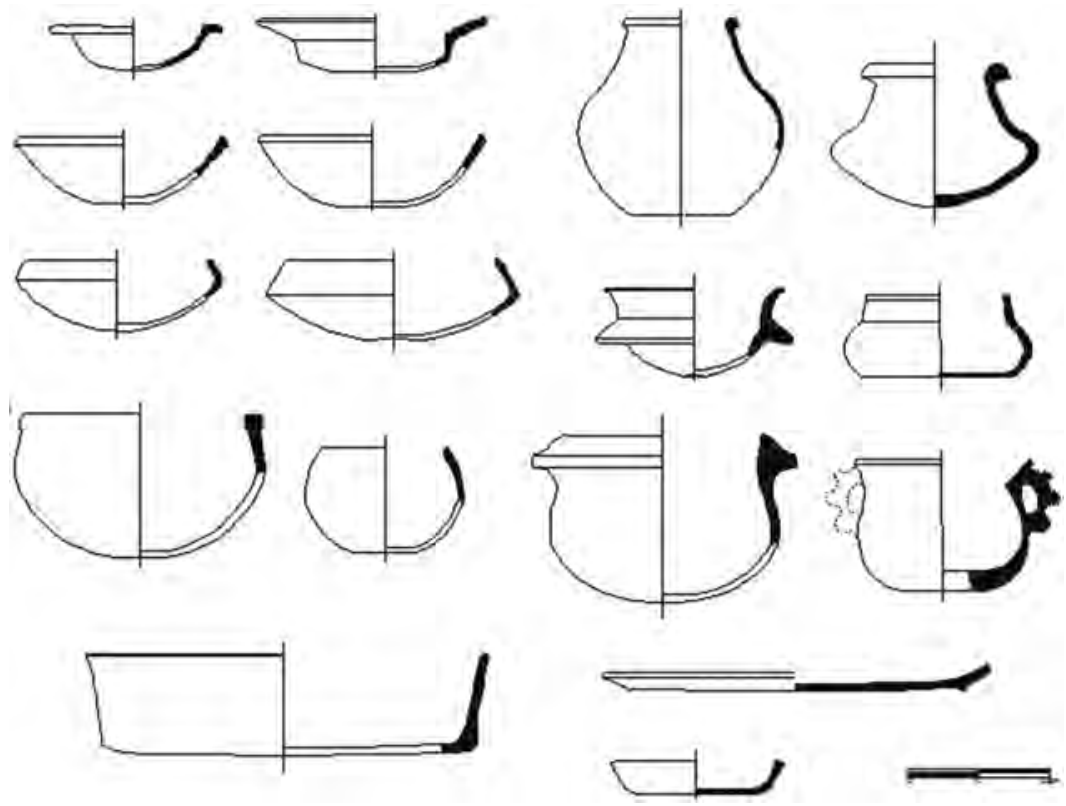

Fig. 4. Variabilidade formal do vasilhame da fase Açutuba. 
importante que se coloca. A fase anteriormente descrita, Açutuba, tem um caráter quase inédito, à exceção de um único artigo publicado por membros da equipe do PAC (Lima et al. 2006). Já a fase Manacapuru foi descrita em detalhes por P. Hilbert, tendo sido definidos seis tipos que, de certa forma, já dão conta de uma caracterização geral do conjunto. Dentro destes tipos há o não-decorado, que perfaz $85 \%$ do total de fragmentos, sempre temperados com o cauixi. Os outros tipos são assim denominados: engobo vermelho, incisão em linhas finas, incisão em linhas largas, incisões duplas e modelado (os tipos de Hilbert encontram-se descritos no apêndice).

As cerâmicas contam com um número relativamente grande de fragmentos decorados, mas a proporção é bem menor do que o observado nas cerâmicas mais antigas. Assim como em qualquer coleção, essas cerâmicas são bastante diversificadas e, em relação à pasta, que varia de acordo com uma série de fatores, somente um tipo se destaca nesta indústria. Este possui, em geral, coloração marrom-acinzentada, queima preferencialmente redutora, e uma consistência densa e pesada, com um maior grau de dureza. $O$ fato da queima ser feita em ambiente redutor não faz com que sua qualidade diminua. Ao contrário, essas pastas são mais duras e resistentes do que aquelas da fase Açutuba. Ainda quanto à pasta, o cauixi é o tempero preponderante, com incidência de outros anti-plásticos misturados a ele, em menor proporção, como o caco moído, nódulos de argila e o cariapé, que é quase inexistente. Há quartzo e hematita na quase totalidade dos fragmentos analisados. Quanto aos acabamentos de superfície, a quantidade de fragmentos que apresentaram polimento ou algum tipo de enegrecimento foi bem maior do que se pôde perceber nas cerâmicas Açutuba. Entretanto, a principal causa deste fato pode ter sido o estado de conservação destes materiais, como já explicitado.

A variabilidade formal é menor e há uma sensível tendência a vasos com formas mais restritivas. Foram encontrados, em diversos sítios, grandes vasos com gargalo carenado (tipo contorno complexo), recobertos por alguidares emborcados sobre eles, que assumiram a função de tampa, muito semelhante àquelas encontradas em urnas funerárias localizadas em sítios-cemitério Paredão. Em dois vasos escavados no sítio Hatahara, foram encontrados dentes humanos, mas ainda é cedo afirmar tratar-se de uma área com fim semelhante.

Do mesmo modo que na fase Açutuba, há uma recorrência em modificar a estrutura do vaso com vistas a tornar os lábios e pescoços dos vasos mais visíveis, proeminentes. Estas serão as áreas preferencialmente utilizadas para aplicação da decoração, em geral, plástica. Mais uma vez, a plasticidade é uma marca desta indústria, tanto no que tange às formas quanto às decorações. De fato, pela tendência a formas restritivas, a presença de flanges labiais é menor que na fase Açutuba, e estes são substituídos pelas bordas extrovertidas. A técnica e o objetivo desta extroversão são sempre os mesmos nos flanges e nos lábios expandidos. A diferenciação entre um e outro é a alteração do volume do vaso. Os flanges labiais não alteram o volume, enquanto os lábios expandidos, sim. Há também uma recorrência de apêndices e apliques modelados, bem como alguns exemplares de estatuetas, sempre decorados através de uma combinação de técnicas que, assim como em Açutuba, apresenta uma grande quantidade de motivos zoomórficos, com preferência pelas aves. Flanges mesiais são ausentes.

Engobo vermelho foi considerado por Hilbert como um tipo da fase Manacapuru, apesar do autor ter notado que em alguns casos ele surge em associação com outras técnicas decorativas, principalmente as incisões. Nossa análise confirmou essa observação de Hilbert, percebendo-se que essa técnica decorativa ocorre na grande maioria das vezes associada a outras, e quase nunca é exclusiva em um fragmento. Concluiu-se, portanto, que o engobo vermelho, ao invés de elemento definidor de tipo, é um complemento das diversas técnicas decorativas. Como diferenciador entre as cerâmicas Manacapuru e Açutuba, no que diz respeito às decorações incisas, está uma maior frequência de incisões duplas ou múltiplas, em geral formando motivos retilíneos e geométricos, ao invés das incisões simples, com motivos curvilíneos e circulares do conjunto mais antigo. Técnicas 
que deixam de aparecer por completo são as excisões e a pintura policrômica. Surgem como acabamentos decorativos as técnicas de ponteado, ungulado e digitado, aplicados comumente nos lábios, e que são muito encontrados também na fase Paredão (Figs. 5 e 6).

\section{Cerâmicas da fase Paredão}

Ao comparar as três fases cerâmicas e seus contextos, da forma como aqui proposta, veremos que os sítios Paredão se encontram no extremo de uma série de características que continuam e que se acentuam ao longo do tempo. Deste modo, há uma profusão maior de sítios na área de pesquisa, assim como suas dimensões também crescem, indicando um aumento da densidade demográfica. Mais do que isso, uma imensa soma de materiais cerâmicos é encon- trada, enterrada sob um profundo e denso pacote de terras pretas antrópicas, carregadas de matéria orgânica. Há, então, evidências mais claras de assentamentos circulares e elipsoidais, compostos por uma série de montículos (mounds e middens), dispostos ao redor de grandes áreas centrais com ausência de materiais, indicando um uso de espaço diferenciado, bem como de outras estruturas que nos informam sobre uma maior alteração da paisagem. A maioria das datações realizadas pelo PAC é de materiais relacionados a esta fase, tornando-a a mais bem conhecida, dentro do projeto, no que concerne à sua cronologia. As datas se concentram em torno dos séculos IX ao XII.

Também este conjunto foi definido por $\mathrm{P}$. Hilbert (1968), em um sítio nos arredores da cidade de Manaus. Ele definiu seis tipos para este material, sendo eles: tipo não-decorado
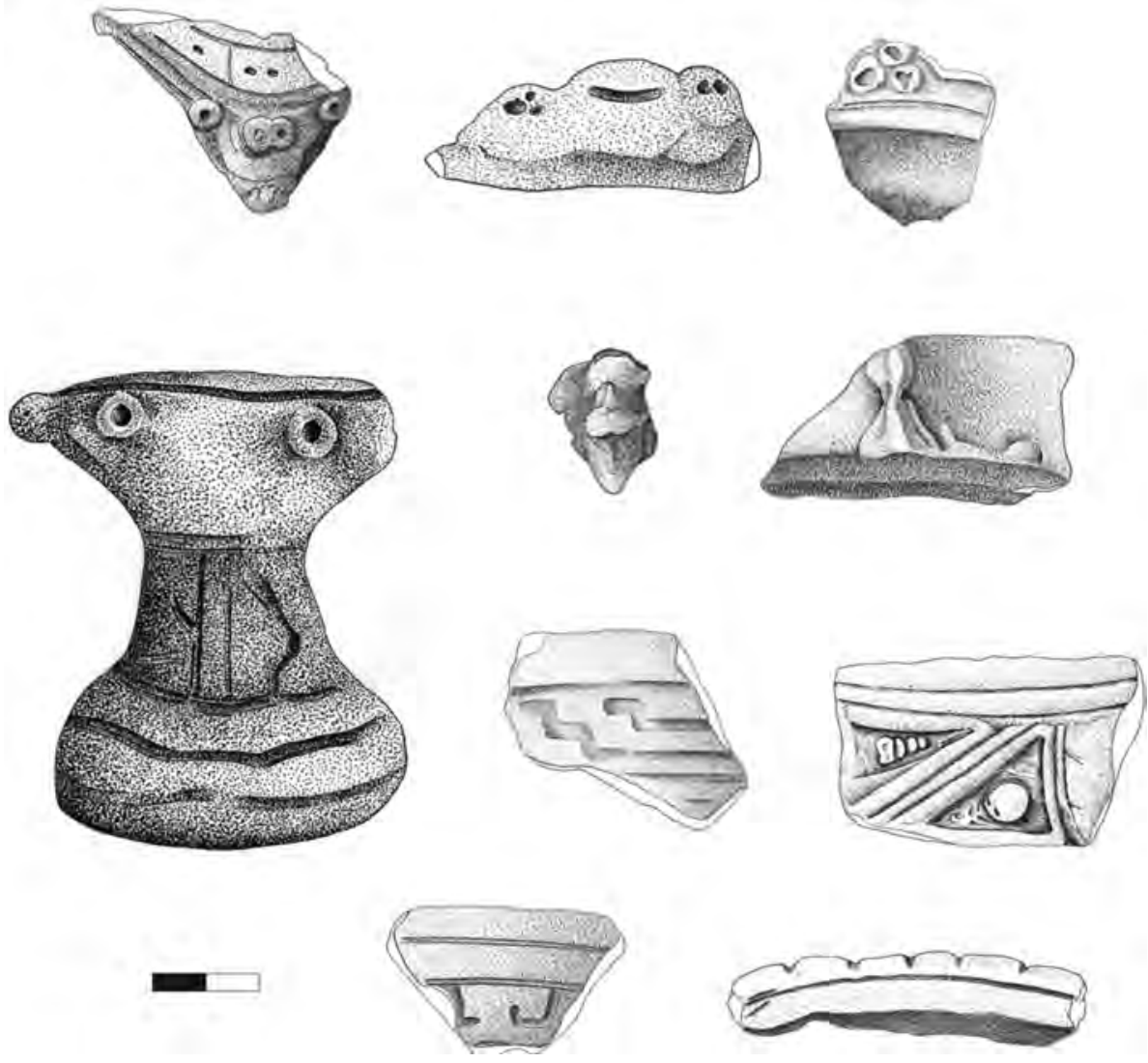

Fig. 5. Fragmentos decorados associados à fase Manacapuru, presente nos sítios Osvaldo e Jacuruxi (desenhos: Val Moraes). 


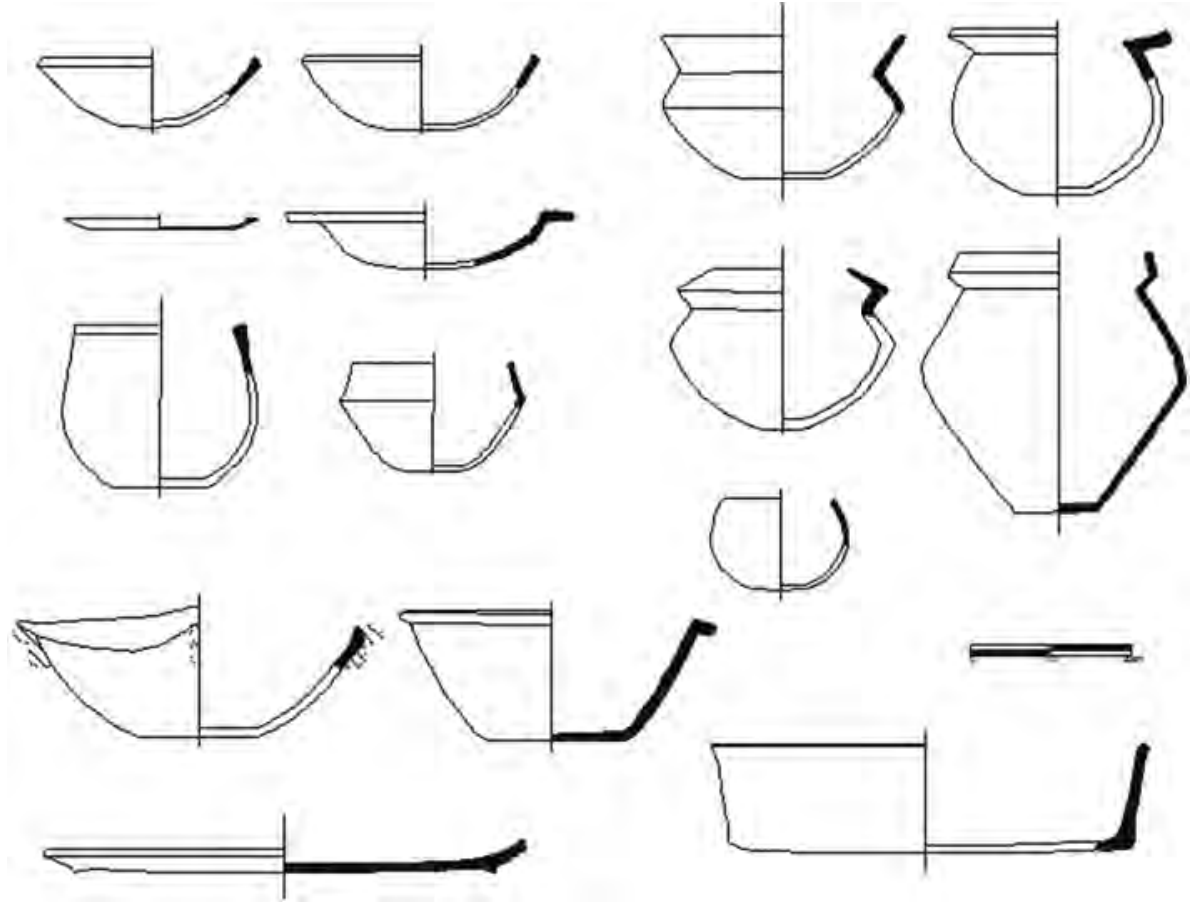

Fig. 6. Variabilidade formal do vasilhame da fase Manacapuru.

(que atende $88 \%$ do material), incisões em linhas finas, pintura vermelha (engobado), incisões duplas, escovado, modelado. Estes tipos foram revistos, justamente em função do grande volume de pesquisas, dentro do PAC, tais como as pesquisas de Donatti (2003), Tamura (2005) e Moraes (2007). A tipologia proposta se baseou nestes trabalhos, em grande parte, o que permitiu a caracterização a seguir.

Comparativamente pode-se dizer que estas cerâmicas apresentam uma pasta peculiar. São quase sempre temperadas por cauixi, embora tenham outras misturas, em menor proporção, como caco moído, quartzo e hematita, e ainda carvão, tal como descrito por Moraes (2007). Embora apresentem um núcleo redutor, em sua maioria, estas cerâmicas são muito bem queimadas, apresentando um alto grau de dureza. Têm cores, em geral, alaranjadas, e paredes muito finas - esta que, afinal, se mostra outra característica deste conjunto -, mesmo em se tratando de vasilhas de grandes dimensões, o que demonstra um altíssimo controle da matéria-prima e dos processos de fabricação. Ao contrário das cerâmicas Açutuba ou Manacapuru, em que há uma tendência a uma maior espessura nas extremidades labiais e não nas paredes, as cerâmicas Paredão apresentam uma grande quantidade de lábios afilados, invertendo esta tendência.

Ainda que haja variações, a pasta mais característica Paredão é a anteriormente mencionada de cor alaranjada, apresentando este acentuado esmero (trata-se do "Laranja A" da ficha de análise e da tipologia Paredão apresentada por Moraes 2007: 144). Exceto os apliques modelados (Fig. 7), a técnica utilizada para a produção desta cerâmica é a de roletes sobrepostos. Embora os tratamentos de superfície mais utilizados sejam o alisamento, seguido pelo polimento, o aspecto deste alisamento é bastante diferenciado dos conjuntos anteriores, devido à maior acuidade no tratamento da pasta.

A variabilidade formal diminui, tornando-se mais padronizada e mais característica, sendo apenas oito as variações formais nos sítios estudados. Entre elas, destacam-se as grandes urnas funerárias, com o formato piriforme e presença de gargalos (Fig. 8). Característicos destas urnas são os apliques antropomórficos (as cabecinhas), colocadas em dois pontos opostos 

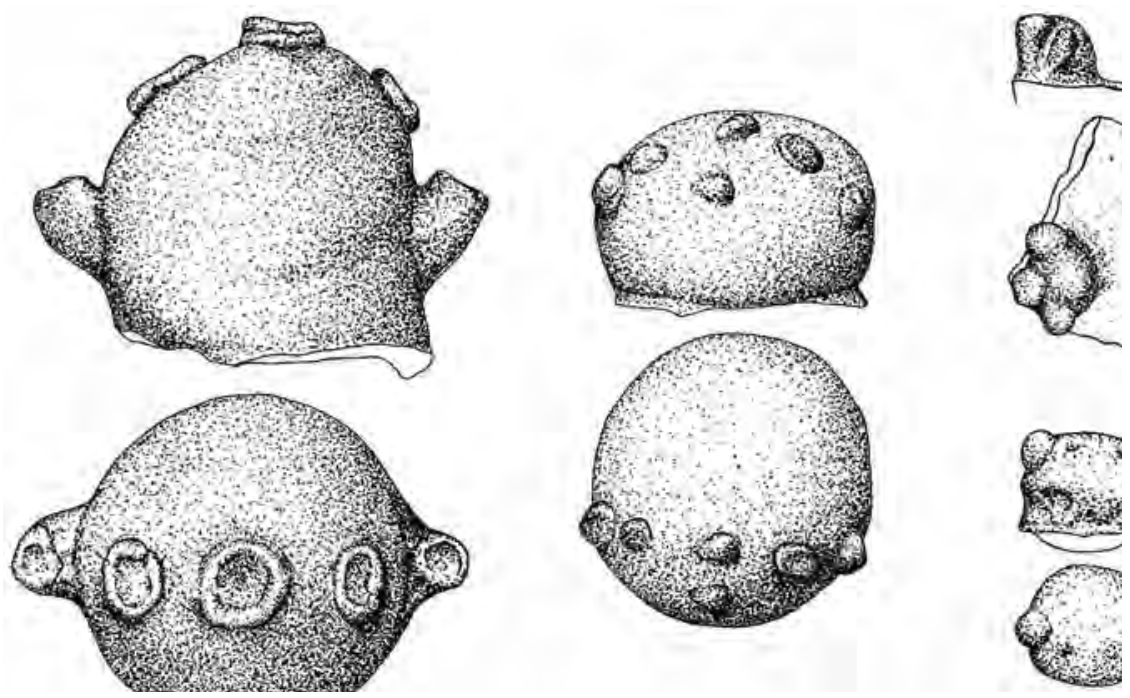

Fig. 7. Apliques modelados Paredão, do sítio Nova Cidade (desenhos: Marcos Brito).
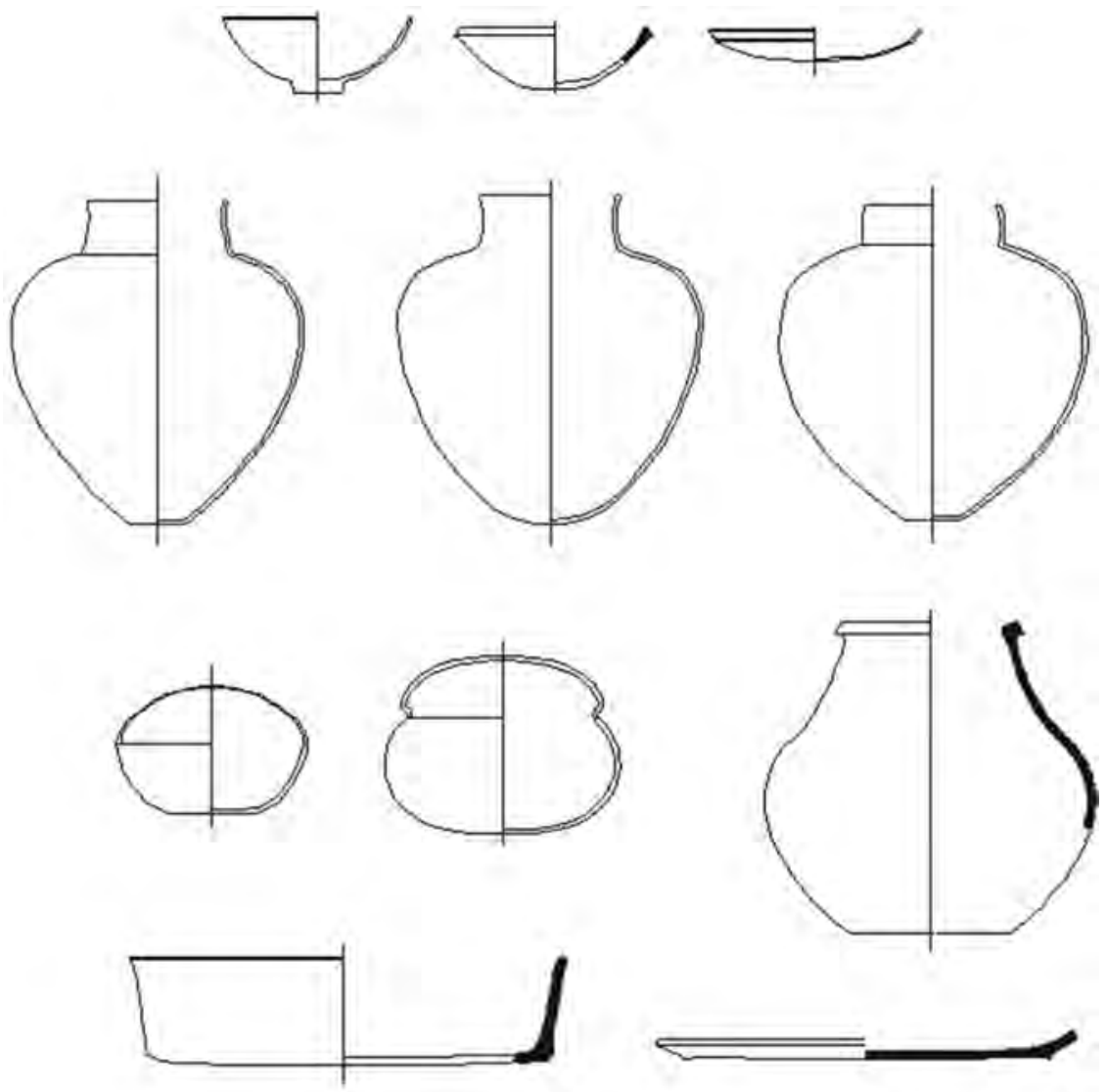

Fig. 8. Variabilidade formal do vasilhame da fase Paredão. 
ao longo do ombro destes vasos. Além disso, tem-se o largo uso de pedestais e alças. Estes são, de fato, elementos diagnósticos desta indústria. Em suma, a variabilidade formal vista nos conjuntos anteriores é substituído por uma maior padronização destas formas, ao passo em que o rebuscamento da decoração parece dar lugar ao esmero da preparação das pastas.

Outro elemento diferenciador desta fase cerâmica é a larga presença de aparatos funerários. São as já mencionadas urnas, que aparecem em grandes concentrações, e geralmente agrupadas em contextos que aparentam ser exclusivamente funerários. Além disso, os montículos funerários também são um indicativo destas práticas. Em oposição a este aparato específico são observados aqueles elementos de uso cotidiano, tais como assadores e alguidares, cuja manufatura não se diferencia muito dos conjuntos anteriormente descritos, e que constituem um número por demais elevado de fragmentos sem características diagnósticas. Ainda em relação aos contextos ligados às atividades quotidianas, há uma enorme abundância de feições associadas a estruturas de combustão, constituídos de trempes feitos a partir de fragmentos grandes e espessos, ou mesmo com barro queimado (Moraes 2007).

As técnicas decorativas mais observadas são as incisões, neste caso executadas com um instrumento pontiagudo muito fino. Trata-se de materiais pertencentes à Tradição Borda Incisa e, de fato, as técnicas decorativas são preferencialmente executadas em regiões próximas à borda. No entanto, deixa-se de observar aquela tendência a uma maior modificação estrutural dos vasos com vistas a acentuar as decorações em suas proximidades distais, fazendo com que esta área tenha menos exclusividade na escolha de onde se aplicar a decoração. Por exemplo, é comum observarmos pedestais decorados, assim como a face interna e inferior de cuias. Estas cuias, quando decoradas, têm incisões espiraladas em seu fundo na face interna, enquanto os pedestais podem ter incisos lineares finos e apresentar engobo vermelho.

As incisões são, na maioria das vezes, em linhas finas e profundas, realizadas por um instrumento pontiagudo, como mencionado. Estas linhas formam motivos geométricos ou espirala- dos, em sua maioria. Assim como ocorre na fase Manacapuru, a extremidade dos lábios pode ter um acabamento ungulado ou ponteado. Pequenas esferas aplicadas e, novamente, ponteado, junto às incisões, são utilizadas nas decorações das cabecinhas. Existe também uma outra categoria de apliques, que são pequenos nódulos de argila modelada, aplicados aos alguidares, em dois ou quatro pontos simétricos, com a função de pequenas alças.

As técnicas de pintura voltam a aparecer, mas possuem certas particularidades que as diferenciam tanto das cerâmicas pintadas Açutuba quanto das Guarita (Tradição Polícroma Amazônica). São aplicadas diretamente sobre a superfície polida da cerâmica, e não sobre camadas de engobo. Têm cores vermelho-escuro ou preto, executadas sobre linhas finas, formando motivos geométricos, espiralados ou em gregas, em muitos casos semelhantes aos motivos incisos. Cabe salientar que a variabilidade estrutural dos motivos Paredão não é grande. Como mencionado acima, seus motivos se apresentam como composições geométricas, triângulos e retângulos espelhados, gregas ou linhas paralelas simples. Há também os motivos curvilíneos e espiralados.

\section{A Tradição Borda Incisa / Barrancóide na Amazônia Central}

Os resultados das análises, quando apresentados e discutidos, foram sempre contrapostos a outros elementos contextuais para possibilitar interpretações mais profundas acerca de seus próprios significados, a fim de obter-se uma abordagem, da maneira mais completa o quanto for possivel, sobre os modos de vida pretéritos com os quais estamos lidando. Vale lembrar que as diferentes coleções, advindas de sítios arqueológicos trabalhados em situações diferenciadas, tiveram também níveis de abordagem distintos. Por exemplo, o tratamento dado às cerâmicas do sítio Açutuba foi mais completo e detalhado do que aquele dado a boa parte das demais coleções. Isto se deu em função dos problemas de pesquisa e da própria disponibilidade dos materiais para estudo. 
Os dados apresentados relacionados às fases Açutuba, Manacapuru ou Paredão, forneceram as bases para o desenvolvimento de uma espécie de glossário para o estudo das cerâmicas da Tradição Borda Incisa / Barrancóide na Amazônia central. Aqui foram compiladas as descrições gerais das cerâmicas e seus atributos, e uma discussão sobre a representatividade de algumas das características. A tabela abaixo apresenta os principais atributos de homogeneizadores e diferenciadores das cerâmicas desta tradição tecnológica (Tabela 4).
Pensar em coleções cerâmicas pressupõe a contemplação de todos os elementos envolvidos no processo de produção, uso, reuso e descarte dos diferentes artefatos. As seguintes etapas foram apreciadas no estudo realizado:

- Seleção, coleta e preparo das argilas.

- O processo de fabricação do vasilhame, incluindo a secagem, queima e os acabamentos de superfície.

- A estrutura do pote.

- Os tratamentos decorativos, das técnicas aos motivos.

\begin{tabular}{|c|c|c|c|}
\hline Atributos & Fase Açutuba & Fase Manacapuru & Fase Paredão \\
\hline Queima & Oxidada predominante & Não-oxidada & Não-oxidada \\
\hline Cauixi como tempero & Presente & Presente & Presente \\
\hline Cariapé como tempero & Presente & Raro & Raro \\
\hline Formas abertas & Mais frequentes & Menos frequentes & Menos frequentes \\
\hline Formas fechadas & Menos frequentes & Mais frequentes & Mais frequentes \\
\hline $\begin{array}{l}\text { Incisões retilíneas } \\
\text { simples ou duplas }\end{array}$ & Menos frequentes & Mais frequentes & Mais frequentes \\
\hline $\begin{array}{l}\text { Incisões curvilíneas } \\
\text { simples ou duplas }\end{array}$ & Mais frequentes & Menos frequentes & Mais frequentes \\
\hline $\begin{array}{c}\text { Excisão ou incisão } \\
\text { sobre engobo vermelho }\end{array}$ & Presente & Ausente & Ausente \\
\hline Ponteado & Ausente & Presente & Presente \\
\hline Acanalado & Presente & Ausente & Ausente \\
\hline Apêndices zoomorfos modelados & Presentes & Presentes & Presentes \\
\hline Lábios cortados & Presentes & Presentes & Presentes \\
\hline Flanges Labiais & Presentes & Menos frequentes & Ausentes \\
\hline Flanges Mesiais & Presentes & Ausentes & Ausentes \\
\hline Engobo vermelho & Presente & Presente & Presente \\
\hline Engobo branco & Presente & Ausente & Ausente \\
\hline Pintura monocrômica & Ausente & Ausente & Presente \\
\hline Pintura policroma & Presente & Ausente & Ausente \\
\hline
\end{tabular}

Tabela 4. Comparação dos atributos entre as diferentes fases cerâmicas. 


\begin{abstract}
- Evidências de utilização, reutilização e descarte.

A divisão aqui proposta (argila, tempero, técnica de manufatura, forma e decoração, uso e reuso) tem fins apenas didáticos, já que, em termos culturais, a combinação desses elementos se dá de maneira interligada, uns influenciando aos outros de acordo com suas propriedades e características de performance. Neste momento, as características das coleções são encaradas de uma perspectiva cronológica, ou seja, são salientados dentro da tecnologia cerâmica os elementos indicativos de continuidade e de mudanças ao longo do tempo, dentro desta tradição tecnológica.
\end{abstract}

\section{Escolhendo e preparando a argila}

Matéria-prima da cerâmica por excelência, sua seleção leva em conta diversos fatores, como a oferta geográfica e sazonal, suas propriedades físico-químicas, ou fatores de ordem simbólica. Contudo, materiais específicos estão normalmente correlacionados a funções específicas (Rye 1981: 26) e, portanto, sua identificação leva a um melhor entendimento de seus usos e significações.

Fontes de argilas são abundantes na Amazônia central, fornecendo inúmeras possibilidades de escolhas tecnológicas. Com a colaboração do Dr. Casimiro Munita (IPEN), este estudo procurou identificar a composição química de fragmentos cerâmicos e de amostras de argila da região, através das mencionadas análises por ativação por nêutrons. Essas análises comparativas propunham verificar a ocorrência ou não de evidências de continuidade nos padrões de escolha tecnológica na produção cerâmica entre as fases Açutuba, Manacapuru e Paredão, e também destas em relação à fase Guarita. No entanto, os resultados não permitiram que estes objetivos fossem alcançados a contento, visto que demandam um estudo específico e focado exclusivamente em tais questões, o que não era o caso. Por outro lado, diversas análises das pastas cerâmicas vinculadas a esses conjuntos permitiram o mapeamento objetivado.

Conjugados às informações das argilas, os dados sobre a seleção dos temperos compuse- ram tal mapeamento, que permitiu uma interpretação sobre a própria organização tecnológica dos conjuntos tratados. É sabido que o uso de anti-plásticos na argila reduz sua plasticidade e facilita seu manuseio, gera uma secagem mais lenta, uma queima mais uniforme, além de dar à cerâmica resistência ao choque térmico e ao impacto (Machado 2005; Rye 1981; Schiffer; Skibo, 1997; Shepard 1956). A análise de argilas e pastas da cerâmica da Amazônia central demonstrou que, durante o processo de seleção e tratamento (limpeza) da argila, houve deliberada intenção na manutenção de algumas de suas impurezas, como grãos de quartzo e hematita. Estes minerais estão presentes em todos os fragmentos analisados, em proporções variadas. A quantidade varia de acordo com os tipos de argila e de formas de vasos, sugerindo que neste caso a escolha - pragmática - do anti-plástico se deu em função da característica de performance da argila em relação ao uso que se pretendia dar aos vasilhames cerâmicos.

Assim, uma vez selecionadas, limpas e tratadas, diferentes argilas são misturadas, e a elas se adiciona o anti-plástico (ou tempero), obtendo-se a pasta que é usada na confecção da cerâmica. Além dos minerais, as pastas analisadas apresentaram também outros tipos de tempero. $\mathrm{O}$ aditivo mais recorrente é o cauixi (esponja de água doce), que pode estar distribuído de modo homogêneo por toda a pasta (em maior ou menor quantidade) ou em forma de pequenos feixes. O cauixi pode ser considerado como uma escolha cultural característica da Tradição Borda Incisa e serviu como base para as tipologias realizadas nas décadas de 50 a 70 na Amazônia, através da seriação por gênero (Meggers; Evans 1970).

Sua disponibilidade é um fator que merece atenção especial. Em primeiro lugar, é encontrado apenas em ambientes relacionados às águas pretas (sejam do rio Negro, de lagos ou de pequenos igarapés). Seu uso é indiscriminado em todo o tipo de ambiente, incluindo aqueles sítios às margens do Solimões, e sua escolha pode ser qualificada como uma opção, em detrimento de outras possiveis, que não foram selecionadas. Aliás, esta opção parece permear toda a Tradição 
Borda Incisa. Outro fator importante é a sazonalidade de sua oferta: a coleta somente é possível em uma época do ano, quando as águas baixam. Assim, percebe-se que a escolha não se deu ao acaso. Apesar de sua coleta só poder ser feita numa época do ano, quando os rios estão na vazante, seu uso é encontrado em abundância nas cerâmicas Borda Incisa de qualquer período. O cauixi aparece ainda na composição das cerâmicas existentes em sítios de água branca, como é o caso do Hatahara, ou seja, além do evidente armazenamento, havia também o transporte.

À parte da presença do cauixi, que poderia ser um elemento homogeneizante de toda esta tradição tecnológica, observam-se importantes variações de seu uso. O próprio tamanho e orientação das espículas varia internamente às fases, de acordo com suas pastas e formas. Entretanto, se olharmos de uma perspectiva mais geral, as cerâmicas mais recentes Paredão, em especial a argila mais característica desta fase, alaranjada, apresentam uma melhor preparação da pasta, em que este cauixi é mais bem pilado e sua pasta mais limpa. De fato, a maneira como o cauixi é processado e utilizado difere perceptivelmente, de uma fase à outra, mesmo sendo visualizado apenas em lupas. Desta forma, o que seria um elemento que homogeneizaria estes conjuntos, na verdade se torna também um diferencial.

Em todos os contextos analisados identificaram-se, em menor proporção, outros tipos de tempero: o cariapé (cinzas da entrecasca de árvore da espécie Licania), caco moído e nódulos de argila. Eles aparecem em proporções reduzidas, e apenas em parte dos fragmentos. No entanto, é importante ressaltar que houve preponderância do cariapé em alguns fragmentos da fase Açutuba em relação aos conjuntos mais tardios.

\section{A fabricação da vasilha}

Grosso modo, a manufatura da cerâmica mostra-se pouco variável no tempo e espaço nos materiais da tradição Borda Incisa. Os vasos analisados são sempre fabricados a partir da técnica de sobreposição de roletes, cujas variações aparecem nas bases, em geral moldadas, ou em alguns apêndices modelados. Contudo, um olhar mais acurado sobre esta técnica ordinária trouxe informações sobre a mudança cronológica neste sistema. Em alguns fragmentos da fase Açutuba pode-se perceber claramente o ponto de junção dos roletes e, em alguns casos, há espaços ocos entre os mesmos, mesmo com todo o rebuscamento decorativo. Quando observamos a junção dos roletes na fase Paredão, estes nem mesmo aparecem, o que demonstra mais uma vez o grande cuidado com o preparo da matéria-prima e o processo de fabrico destas vasilhas mais recentes.

Feita sua estrutura, o pote será seco para somente então passar pelo processo de queima, e é depois da queima que a argila se torna cerâmica. Conforme já explanado, as características da pasta cerâmica derivam de diversos fatores, entre eles a queima. As variações observadas entre os conjuntos analisados dizem respeito, provavelmente, ao grau atingido pela cerâmica durante a queima.

Também quanto aos acabamentos dados à superfície dos objetos cerâmicos é necessário um olhar apurado, para perceber sutis diferenças entre as indústrias, mesmo em relação ao alisamento, que é sempre o mais utilizado. A este efeito que se nota em certos fragmentos, obtidos a partir de um bom alisamento e que causa uma impressão de polimento, se deve justamente ao tratamento dado a argila paredão. À exceção do alisamento, se observarmos as frequências dos tratamentos nos diferentes sítios descritos, percebe-se uma maior frequência de acabamentos tais como polimento e até a aplicação de resina nos fragmentos mais antigos.

As cerâmicas apresentam padrões de queima variados, mas pode-se perceber uma mudança entre as fases Açutuba e Manacapuru. A fase mais recente apresenta, na maioria dos fragmentos, queima não oxidada, enquanto que na fase Açutuba, a maior parte dos potes são oxidados. Essa diferença não acarreta na qualidade da queima já que, neste caso, as cerâmicas com queima em ambiente não oxidado parecem ter maior grau de dureza. 
A queima paredão é um caso à parte. As análises das fraturas dos fragmentos indicam uma cor acinzentada, típica de uma queima feita em ambientes redutores. É uma queima completa, que quase atinge o estágio de vitrificação da argila. De fato, a cerâmica paredão é muito característica tanto por sua cor alaranjada como pela sua maior dureza.

\section{Estrutura do pote: variabilidade formal}

A morfologia do vasilhame relacionado a esta tradição tecnológica foi apresentada na discussão sobre as fases arqueológicas. Os pontos que valem ser salientados residem, basicamente, na perspectiva cronológica. Tanto a variabilidade formal quanto a complexidade dos contornos apresentam sensíveis alterações ao longo do tempo. A começar pelas cerâmicas da fase Açutuba, onde se vê uma profusão de formas, diminuindo em relação à fase Manacapuru e reduzindo ainda mais na fase Paredão - respectivamente, dezesseis, treze e oito tipos identificados nos materiais trabalhados. A essa redução da variabilidade, soma-se um aumento da quantidade de materiais e, principalmente, uma crescente padronização das formas.

À parte da variabilidade inerente às coleções cerâmicas, que remetem a funções dadas (formas restritivas e irrestritivas), é a estrutura geral do vasilhame que varia ao longo do tempo. Um exemplo disso, como se viu, é a tendência a modificar estruturalmente o pote de forma a salientar o local a ser decorado, com o uso de diversos artifícios. É o caso, no conjunto mais antigo, dos flanges labiais, bordas extrovertidas e lábios expandidos, que sempre serão decorados. Esta tendência continua, embora os recursos sejam diferentes. No conjunto mais recente, Paredão, já não se vê uma maior espessura dos lábios, ao contrário, estes são afilados. Neste sentido, um flange, um pedestal ou um gargalo não são apenas suportes à aplicação de uma ou outra decoração, mas são também uma decoração em si. Assim, a própria forma se mostra um vetor de mensagens, tanto quanto uma decoração plástica ou pintada, que pode impingir sentidos muito variados, como marcadores de identidade ou de status social.
A arte de dar forma ao barro: decorações plásticas

A plasticidade é a característica mais marcante dessas cerâmicas. A modificação formal das bordas para a obtenção de flanges, gargalos e pescoços, anteriormente mencionada, pode ser considerada como um elemento decorativo, uma vez que a intenção é não só criar um suporte visível para a aplicação da decoração, mas que a forma do vaso adquira um aspecto decorativo. As incisões de todos os tipos, finas, largas, simples, duplas ou múltiplas são os elementos decorativos mais recorrentes nestas cerâmicas. Outras técnicas também são utilizadas, como o ponteado, geralmente aplicados nos lábios e nos apêndices da fase Manacapuru e Paredão. Há também nestas duas fases o uso do ungulado que, da mesma forma que o ponteado e o digitado, são aplicados na extremidade dos lábios. Este último é quase ausente na fase Açutuba.

No que se refere à decoração plástica, as fases Açutuba e Manacapuru apresentam alguns pontos em comum, como as incisões e a modelagem. Estas duas técnicas aparecem na cerâmica Paredão, tendo as incisões uma proporção muito maior que a modelagem. No entanto, outras técnicas marcam sensivelmente as diferenças entre estes três conjuntos. As cerâmicas Paredão e Manacapuru priorizam a decoração incisa simples ou dupla, respectivamente, sempre em linhas finas, formando motivos geométricos. O ponteado profundo é também muito utilizado nos dois conjuntos. Já nas cerâmicas da fase Açutuba verifica-se maior ênfase à modelagem, ao acanalado e à excisão, enquanto as incisões priorizam motivos curvilíneos e espiralados, do mesmo modo como ocorre com a cerâmica Paredão. De fato, o ponteado é raríssimo na fase Açutuba, assim como não ocorre excisão na cerâmica Manacapuru.

Quanto aos apliques, os motivos zoomórficos são muito comuns nas fases Açutuba e Manacapuru, e também ocorrem na fase Paredão. No entanto, nesta última aparece outra categoria de apliques, em formas antropomórficas, as famosas "cabecinhas", aplicadas nos ombros das urnas. 


\section{Um toque de cor: decorações crômicas}

Ainda que as decorações plásticas sejam marca desta tradição tecnológica, a presença de cores também é muito recorrente. Na verdade, a grande recorrência é devida ao engobo vermelho. Este consiste na aplicação de uma camada de tinta à base de óxido de ferro na superfície da cerâmica antes da queima. Existe uma grande variação de tonalidades de vermelho, entre cores quase alaranjadas e róseas a tons bastante escuros, quase púrpuros. As duas fases descritas por Hilbert tiveram tipos definidos pela presença do engobo vermelho, que sempre aparece junto a outras técnicas de decoração plástica, geralmente incisões. A fase Açutuba, identificada num momento posterior, não é diferente, ou seja, este é um traço característico em todos os conjuntos Borda Incisa.

Um diferencial da fase Açutuba é o engobo branco, uma fina camada de argila branca aplicada na superfície da cerâmica antes da queima. Pode ter função utilitária, como impermeabilizante, ou decorativa, servindo como base para a aplicação da pintura. Apesar de ser traço diagnóstico das cerâmicas associadas à fase Guarita, a utilização do engobo branco como recurso decorativo é uma característica diagnóstica também da fase Açutuba, e define, juntamente com outros atributos, essa indústria. Na verdade, Meggers notou a presença de engobo branco em alguns fragmentos da então chamada fase Manacapuru (desmembrada como fase Açutuba), porém os considerou como ocorrências isoladas. A alta incidência de engobo branco em contextos unicomponenciais da fase Açutuba, bem preservados e caracterizados, e sua aplicação em cerâmicas cujos elementos tecnológicos são muito distintos dos materiais correspondentes à fase Guarita, excluem qualquer possibilidade de intrusão. Assim, consideramos o engobo branco como traço diagnóstico também da fase Açutuba, junto à pintura policrômica, detectada entre os materiais associados à fase Açutuba em todos os sítios estudados. Essa técnica consiste na aplicação de pintura em diferentes tonalidades de vermelho ou preto, sobre a camada de engobo branco.
A observação dos fragmentos pintados nos permitiu inferir a sequência de operações requeridas à realização desta decoração. Uma primeira camada de engobo branco era aplicada ao pote já constituído e parcialmente seco. $\mathrm{O}$ engobo branco pode ser obtido a partir de um tipo específico de argila, o caulim, bastante comum na região. A essa camada sobrepõe-se uma fina e delicada pintura, que pode ser preta ou de diferentes tonalidades de vermelho ou vinho. Essas cores compõem motivos geométricos, retilíneos e/ou curvilíneos. A etapa seguinte consistia na queima dos vasos, que deve ter ocorrido sob alta temperatura em ambiente fechado, já que a pasta tem coloração clara e homogênea. Finalmente, uma última camada de pintura alaranjada podia ser aplicada, completando a composição final do motivo.

Com exceção da fase Pocó, no baixo Amazonas, até o presente momento não havia registros da presença de policromia tão antiga na Amazônia brasileira (Hilbert; Hilbert 1980). Nas terras baixas, ela foi detectada apenas na bacia do rio Orinoco, Venezuela, e no Caribe. Foi atribuída à série Saladóide, cujas formas de relação com a série Barrancóide também fomentou acirrados debates. De qualquer modo, a relação entre essas duas tradições é clara na Venezuela, e parece ocorrer também na Amazônia central, nos materiais associados à fase Açutuba. Mais uma vez, podemos observar a presença de características típicas da fase Guarita ocorrendo em cerâmicas da fase Açutuba, que é pelo menos mil anos mais antiga. Embora as cerâmicas correspondentes a essas duas fases sejam decoradas através da mesma técnica apresentada antes, a policromia, ela ocorre de maneira bastante diferente, com um resultado final que é também distinto.

Mas a presença de pintura não é exclusiva da fase Açutuba. Conquanto muito diferente, ela aparece na fase Paredão. Ao invés de ocorrer sobre engobo, ela é aplicada diretamente sobre a pasta cerâmica, em algumas ocasiões muito bem alisada ou polida, e consiste em linhas finas nas cores preta e vermelha, formando motivos geométricos, em gregas ou espiralados, semelhantes aos motivos incisos. Não há, porém, qualquer associação entre este tipo de pintura e as demais decorações plásticas no mesmo fragmento ou vasilha. 
Forma, função e características de performance

Para um entendimento mais amplo de um conjunto arqueológico é importante que se entenda os significados de sua variabilidade formal. A forma está intrinsecamente ligada aos usos que serão dados aos objetos, depois de prontos. Este foi um ponto abordado na variabilidade tipológica e, mais do que isso, as características morfológicas foram definidoras dos tipos, como um meio de se compreender aspectos mais gerais das sociedades que produziram, utilizaram e descartaram esses objetos. Está claro que formas específicas exigem tipos particulares de argila, tempero e tratamento, e que isto está relacionado às diferentes utilizações que terão os artefatos cerâmicos, bem como as suas características de performance. Embora aí resida boa parte do entendimento das escolhas tecnológicas, tais aspectos variam muito dentro de cada indústria. Sua análise foi feita, mesmo abordando apenas traços pontuais, por meio das comparações tipológicas e das próprias fases cerâmicas.

Como já discutido em parágrafos anteriores, através da análise destes materiais foi possivel detectar que determinadas categorias de objetos, com inferências de finalidades cotidianas, estão vinculadas a uma maior variabilidade em termos de processos de fabricação e de escolhas de matéria-prima, mas não de sua morfologia, que sofre pequenas mudanças com o passar das gerações. Ao contrário, materiais que apresentam decorações específicas, que os tornam diagnósticos de diferentes períodos cronológicos, apresentam uma menor variação interna às formas ou tipos, mas são suscetíveis a uma drástica mudança formal, tecnológica e decorativa.

Uso e reuso: evidências de utilização, reutilização e descarte

Muitas vezes, a utilização deixa marcas na superfície da cerâmica que podem ser, posteriormente, observadas e inferidas. Exemplos disso podem ser as marcas de atrito e desgaste de um vaso e os vestígios de fuligem de um artefato que vai ao fogo. Porém, boa parte dos materiais apresentava sinais evidentes de desgas- te relacionado à passagem do tempo e às condições de preservação, nem sempre compatíveis a observações desta natureza. A análise atentou para estes fatores, embora não tenha tido o sucesso desejado, com exceção da fuligem, que se preserva com mais facilidade. Na verdade, muitos dos fragmentos apresentaram estas marcas, e corroboraram em parte nossas suposições de uso, uma vez que estavam sempre presentes nos assadores, alguidares e cuias - embora estivessem também presentes em alguns materiais decorados. Isto baseou, inclusive, algumas das suposições sobre continuidades e mudanças ao longo do tempo.

Os próprios padrões de descarte podem trazer muitas questões importantes sobre os povos que ali estiveram, como é o caso dos pequenos montes de refugos (middens), que congregavam tudo aquilo que se encontrava fora de uso, a partir de um descarte em locais específicos, provavelmente próximos das habitações.

Alguns dos fragmentos analisados também apresentaram evidências de usos para os quais não tinham sido originalmente criados, em uma forma de reutilização. De fato, estas evidências de reutilização estão presentes em todo o registro da Amazônia central, em duas escalas. Uma delas remete ao próprio objeto, em que cacos de potes de diferentes tamanhos e espessuras foram aproveitados para outras funções, diferentes daquelas dos quais foram inicialmente produzidos. Este foi o caso das rodelas de fuso, dos vasos remendados e das trempes provenientes de coleções advindas de diversos sítios. Uma segunda categoria tem uma amplitude muito maior, e nem sempre este reuso foi feito pelas populações que outrora produziram os vasos, agora reduzidos a cacos. É o caso, por exemplo, da utilização dos fragmentos para a construção de montículos artificiais, bem como de diversas feições encontradas nos sítios em questão. Desta forma, a cerâmica utilizada como material construtivo de estruturas de tal magnitude é um perfeito exemplo de reutilização de artefatos após seu descarte. Do mesmo modo, cerâmicas são constantemente re-utilizadas ao se incluir o caco moído - como tempero - em novos vasos cerâmicos, adicionando-se o velho vaso a um novo vaso. 


\section{Considerações finais}

Longe de ser uma região arqueologicamente virgem, a Amazônia central foi foco de distintas hipóteses de ocupação do norte da América do Sul, tendo tido sua arqueologia explorada desde a primeira metade do século XX, ainda que tais pesquisas tivessem um caráter pontual. As coleções resultantes dessas pioneiras pesquisas, como as que P. Hilbert iniciou entre 1955 e 1961, lançaram as bases tipológicas para o estudo da região (1968).

O foco deste artigo visava apresentar estudos relativos a um maior entendimento dos materiais vinculados à Tradição Borda Incisa (Meggers; Evans 1961, 1983) ou Barrancóide (Lathrap 1970a 1970b; Gomes 2002). Para tanto, voltou-se a uma revisão das tipologias anteriormente propostas através do estudo de materiais provenientes de sítios arqueológicos situados na área de confluência entre os rios Negro e Solimões. Como passo inicial da presente pesquisa, procedeu-se a um refinamento da tipologia de Hilbert, calcado nas coleções arqueológicas dos sítios escavados pelo PAC.

A metodologia de Hilbert difere bastante da utilizada na pesquisa, sendo que as tipologias resultantes não são diretamente comparáveis. No entanto, as características com as quais ele pensou as fases cerâmicas convergiram, em muitos aspectos, com o que foi identificado neste trabalho. Ou seja, as duas tipologias, estabelecidas através de diferentes sítios arqueológicos, de outros métodos, e principalmente através de vieses teórico-interpretativos distintos, levaram a resultados semelhantes, o que veio a corroborar certa coerência dos conjuntos, para além dos subjetivos parâmetros classificatórios.

Neste caso, porém, se procurou ultrapassar a simples identificação de fases arqueológicas e sua circunscrição geográfica. Mais do que isso, visou-se entender as relações culturais e históricas subjacentes a elas. Neste sentido, o estudo não se resumiu a uma simples revisão de trabalhos anteriores, mas sim reflete um aprofundamento de questões já clássicas na arqueologia amazônica, tais como a validade heurística e epistemológica da Tradição Borda Incisa, de onde vem, inclusive, seu ineditismo.

A sequência material correspondente às fases Açutuba, Manacapuru e Paredão pode, então, ser explorada com vistas a discutir a representatividade dos materiais encontrados explorando o conceito amplo e genérico de Tradição, que envolve não só sua representação material, mas também sua dimensão cultural e histórica. Este trabalho versa, portanto, sobre como se dão mudanças em certos aspectos da vida humana em sociedade, e como estas interferem em sua cultura material e contexto, objetos, por excelência, da arqueologia. Assim, as padronizações materiais encontradas nos materiais da Tradição Borda Incisa foram pensadas enquanto indicativas de uma continuidade cultural colocada em perspectiva a partir de sua inserção em um largo quadro social, econômico e político, de caráter genérico e sistêmico que, por sua materialidade, se torna historicamente datável. 
LIMA, H.P.; NEVES, E.G. Incised Rim/Barrancoid Ceramics in the Central Amazon. R. Museu Arq. Etn., São Paulo, n. 21, p. 205-230, 2011.

\begin{abstract}
The ceramic chronology of central Amazon has been long debated. Some of the prime hypotheses about human occupation in the area are now been re-evaluated under a strong empirical database allied to a new theoretical and analytical corpus. This article presents part of the results of the ceramic analysis carried on a $\mathrm{PhD}$ research conducted within the Central Amazon Project (MAE-USP). The data compiled in this paper also provides pointers to reassess the use of traditional archaeological concepts such as phases and traditions. In the confluence area of the Negro and Solimões rivers, this permits to construct a chronology that is based on an understanding of the relationships between the Açutuba, Manacapuru and Paredão phases, related to Incised Rim/Barrancoid Tradition.
\end{abstract}

Key words: Amazonian archaeology - Ceramics - Chronology - Central Amazon.

\title{
Referências bibliográficas
}

ABREU, M.E.

2000 Estudo dos padrões do uso do espaço no sitio Osvaldo (Am-Ir-09). Relatório de Iniciação Científica encaminhado à FAPESP - Museu de Arqueologia e Etnologia. São Paulo: Universidade de São Paulo.

A LMEIDA, F.

2008 O Complexo Tupi da Amazônia Oriental. Dissertação de Mestrado. São Paulo, MAE-USP.

BANDEIRA, A.

2008 O Sambaqui do Bacanga na ilha de São Luís - Maranhão: um estudo sobre a ocorrência cerâmica no registro arqueológico. Dissertação de Mestrado. São Paulo, MAE-USP.

BORGES, W.; COELHO, D.

2003 Levantamento e estudo dos sítios arqueológicos da margem do Lago Grande, AM e análise dos vestígios cerâmicos do sítio arqueológico Açutuba, Iranduba/ AM. Relatório de Análise Estatística sobre o Projeto - Instituto de Matemática e Estatística. São Paulo: Universidade de São Paulo. (RAE-CEA-03P12)

BROCHADO, J.

1989 A expansão dos tupi e da cerâmica da tra- dição policrômica amazônica. In: Dédalo, São Paulo, 27: 65-82.

DIAS, A.

2003 Sistemas de assentamento e estilo tecnológico: uma proposta interpretativa para a ocupação pré-colonial do Alto Vale do Rio dos Sinos, Rio Grande do Sul. Tese de Doutorado. São Paulo, MAE-USP.

DONATTI, P.

2003 A ocupação pré-colonial da área do lago Grande, Iranduba, AM. Dissertação de Mestrado. São Paulo, MAE-USP.

GOMES, D.

2002 Cerâmica Arqueológica da Amazônia: Vasilhas da Coleção Tapajônica do MAE-USP. São Paulo: EDUSP/FAPESP/Imprensa oficial do Estado.

HILBERT, P.

1968 Archäologische Untersuchungen am Mittlern Amazonas. Berlin: Dietrich Reimer Verlag.

HILBERT, P.; HILBERT, K.

1980 Resultados Preliminares da Pesquisa Arqueológica nos Rios Nhamundá e Trombetas, Baixo Amazonas. Boletim do Museu Paraense Emilio Goeldi, Antropologia, 75: $1-11$. 
LATHRAP, D.

1970a The Upper Amazon. London: Thames and Hudson.

1970b Review of Archäologische Untersuchungen am Mittlern Amazonas, by Peter Hilbert. American Antiquity, 35 (4): 499-501.

LIMA, $\mathrm{H}$

2008 História das Caretas: a Tradição Borda Incisa na Amazônia Central. Tese de Doutorado. São Paulo, MAE-USP.

LIMA, H.; NEVES, E.; PETERSEN, J.

2006 A fase Açutuba: um novo complexo cerâmico na Amazônia central. Arqueologia Sul-Americana, 2 (1): 26-52.

MACHADO, J.

2005 A formação de montículos artificiais: um estudo de caso no sítio Hatahara, Amazonas. Dissertação de Mestrado. São Paulo, MAE-USP.

MEGGERS, B.

1971 Amazonia: Man and Culture in a Counterfeit Paradise. Chicago: Aldine/Atherton.

1990 Reconstrução do comportamento locacional pré-histórico na Amazônia. Boletim do Museu Paraense Emílio Goeldi, Série Antropologia, 6 (2): 183-203.

MEGGERS, B.; EVANS, C.

1957 Archaeological Investigations at the Mouth of the Amazon. Washington, D.C.: Bureau of American Ethnology, Bulletin nº 167.

1961 An experimental Formulation of Horizon Styles in the Tropical Forest Area of South America. In: Lothrop, S. (Ed.) Essays in Precolumbian Art and Archaeology. Cambridge, Harvard University: 372-88.

1970 Como Interpretar a Linguagem da Cerâmica: Manual para Arqueólogos. Washington, D.C.: Smithsonian Institution.

1983 Lowland South America and the Antilles. In: Jennings, J. (Ed.) Ancient South Americans. San Francisco: W.H. Freeman.

MORAES, C.P.

2007 Levantamento arqueológico das áreas de entorno do Lago do Limão, município de Iranduba - AM. Dissertação de Mestrado. São Paulo, MAE-USP.

NEVES, E.G.

2000 Levantamento Arqueológico da Área de Confluência dos Rios Negro e Solimões, Estado do Amazonas. Relatório de Atividades apresentado à FAPESP - Museu de Arqueologia e Etnologia. São Paulo: Universidade de São Paulo.

2003 Levantamento arqueológico da área de confluência dos rios Negro e Solimões, Estado do Amazonas: Continuidade das escavações, análise da composição química e montagem de um sistema de informações geográficas. Relatório de Atividades apresentado à FAPESP - Museu de Arqueologia e Etnologia. São Paulo: Universidade de São Paulo.

2008 Cronologias Regionais, Hiatos e Continuidades na História Pré-Colonial da Amazônia. Relatório de Atividades Referente ao Projeto Temático - FAPESP. Museu de Arqueologia e Etnologia. São Paulo: Universidade de São Paulo.

NEVES, E.G.; COSTA, F.

2001 Resgate Emergencial do Sítio Arqueológico Nova Cidade, Manaus-AM (Parte 1). Relatório encaminhado ao Ministério Público Federal e IPHAN 1a Superintendência Regional - Manaus/AM.

NEVES, E.G.; COSTA, F.; LIMA, H.

2004 Resgate Emergencial do Sítio Arqueológico Nova Cidade, Manaus-AM (Parte 2). Relatório encaminhado ao Ministério Público Federal e IPHAN 1a Superintendência Regional - Manaus/AM

NEVES, E.G.; CASTRO, M.; COSTA, F.; LIMA, H.; PY-DANIEL, A.

2007 Cronologias Regionais, Hiatos e Continuidades na História Pré-Colonial da Amazônia. 1 Relatório Parcial do Projeto Temático, processo no 05/606003-4, apresentado à FAPESP.

PEIXOTO, C.; OKURA, R.

2003 O significado da variabilidade da Fase Manacapuru na Amazônia Central. Relatório de análise estatística sobre o projeto Instituto de Matemática e Estatística. São Paulo: Universidade de São Paulo. (RAE - CEA - 03P32).

PORTOCARRERO, R.

2007 A variabilidade espacial no sítio Osvaldo: estudo de um assentamento da Tradição Barrancóide na Amazônia Central. Dissertação (Mestrado em Arqueologia) - Museu de Arqueologia e Etnologia. São Paulo: Universidade de São Paulo.

RYE, O.

1981 Pottery technology: principles and reconstruction. Washington, D.C.: Taraxacum.

SCHAAN, D.

2004 The Camutins Chiefdom: Rise and Development of Social Complexity on Marajó Island, Brazilian Amazon. Tese de Dou- 
torado. Departamento de Antropologia. Universidade de Pittsburgh, Pittsburgh.

2007 Uma Janela para a História Pré-colonial da Amazônia: Olhando Além - e apesar - das Fases e Tradições. Boletim do Museu Paraense Emílio Goeldi, Ciências Humanas, 2 (1): 77-89.

SCHIFFER, M.; SKIBO, J.

1997 The explanation of Artifact Variability. American Antiquity, 62 (1): 27-50.

\section{SHEPARD, A.}

1956 Ceramics for the Archaeologist. Washington, D.C.: Carnegie Institution of Washington (Publication n. 609).
SILVA, F.A.

2000 As tecnologias e seus significados: um estudo da cerâmica Asuriní do Xingu e da cestaria dos Kayapó-Xikrin sob uma perspectiva etnoarqueológica. Tese (Doutorado em Antropologia) - Faculdade de Filosofia, Letras e Ciências Humanas. São Paulo: Universidade de São Paulo.

\section{TAMURA, A.}

2005 A Ocupação pré-colonial do sítio Lago Grande. Relatório Parcial de IniciaçãoCientífica apresentado à FAPESP. São Paulo, MAE-USP.

Recebido para publicação em 22 de julho de 2011. 